Research Article

\title{
Optimization Effects of Load Reduction for Earth Pressure on High-Filled Cut-and-Cover Tunnels Using the Discrete Element Method
}

\author{
Bentian Yu, Junying $\mathrm{Xia}^{2}$ Sheng $\mathrm{Li} \mathbb{D}^{3},{ }^{3}$ and Liangliang Zhao $\mathbb{D}^{4}$ \\ ${ }^{1}$ National and Provincial Joint Engineering Laboratory of Road \& Bridge Disaster Prevention and Control, \\ Lanzhou Jiaotong University, Lanzhou, 730070, Gansu, China \\ ${ }^{2}$ College of Civil Engineering, Lanzhou Jiaotong University, Lanzhou, 730070, Gansu, China \\ ${ }^{3}$ National and Provincial Joint Engineering Laboratory of Road \& Bridge Disaster Prevention and Control, \\ Lanzhou Jiaotong University, Lanzhou, 730070, Gansu, China \\ ${ }^{4}$ College of Civil Engineering, Southwest Jiaotong University, Chengdu, 610031, Sichuan, China
}

Correspondence should be addressed to Sheng Li; lis@mail.lzjtu.cn and Liangliang Zhao; 0218177@stu.lzjtu.edu.cn

Received 24 July 2021; Accepted 22 September 2021; Published 11 October 2021

Academic Editor: Xinyu Ye

Copyright (c) 2021 Bentian Yu et al. This is an open access article distributed under the Creative Commons Attribution License, which permits unrestricted use, distribution, and reproduction in any medium, provided the original work is properly cited.

In the Northwestern part of Loess Plateau of China, the ravine and valley are numerous; therefore, high-filled cut-and-cover tunnels (HFCCTs) play a major role in meeting traffic needs and creating a great deal of usable land. However, due to higher backfill soil, a high earth pressure is generated, which affects the safety of HFCCTs. To this end, using the discrete element method (DEM), three load reduction measures were introduced to evaluate HFCCT: the cross section types of HFCCT; the combination of optimized cross section type with load reduction using expanded polystyrene (EPS); and the combination of optimized cross section type with load reduction using the EPS and concrete wedge (CW). We evaluated changes in earth pressure of HFCCTs with reference to the density and laying position of EPS and the height as well as width of CW. Parametric DEM studies were performed to characterize these influential factors. It was found that different cross section types of HFCCT have a certain influence on earth pressure distribution, and load reduction effects of EPS were extremely obvious, resulting in a sharp drop in vertical earth pressure on top of HFCCT and a slight growth in lateral earth pressure on the sides of HFCCT. Moreover, installation of CWs reduced the VEP and LEP of HFCCT. These factors were also shown to exert important effects on load reduction mechanisms of HFCCT. Based on their influence on earth pressure of HFCCT from a macroscopic and microscopic view, optimal values for influential factors were derived.

\section{Introduction}

To overcome the challenges associated with mountains and less land in transportation network construction in the Loess Plateau of northwest China, a large number of high-filled cut-and-cover tunnels (HFCCTs) are applied. However, the thickness of conventional HFCCT lining structure has become a fault, and the shrinkage cracks produced by hardened concrete cause longitudinal cracking of the structure and affect its durability. Such high fill induces excessive earth pressure above the tunnel, severely affecting the safety of the HFCCT. Therefore, reasonable load reduction measures should be performed to improve the safety of HFCCT. However, load reduction materials cannot achieve load reduction effects for HFCCT with ultrahigh backfills; therefore, it is necessary to increase backfill soil height and improve the bearing force capacity of HFCCT through a combination of structural cross section type optimization and laying load reduction materials. It is important to evaluate the impact of different cross section types and characteristics of load reduction materials on earth pressure distribution around HFCCT.

Studies on load reduction of high backfill structures have been performed. For deeply buried culverts, Marston [1] 
proposed and verified the ITI unloading method, which means laying compressible flexible materials on top of the culvert to reduce earth pressure. Subsequently, they evaluated the effects of structural-soil interactions by laying flexible materials on top of the culverts. Flexible materials for load reduction include straw [2,3], sawdust [4], leaves [5], and expanded polystyrene (EPS) [6-9]. Geosynthetics have also been shown to play a certain role in load reduction on underground pipelines by Zheng et al. [10], Ahmed et al. [11], and Naggar et al. [12]. Based on the theory of culvert load reduction, Li et al. [13-17] performed a series of studies on load reduction in HFCCT so as to inform effective load reduction measures and evaluate various factors affecting soil arch effects of HFCCT.

In addition, the effects of cross section type of high backfill structures on earth pressure were evaluated. Various types of culverts, such as box culvert [8,18-22], arch culvert [23], tubular culvert [24-28], and cover culvert [29] have been evaluated. For HFCCT, the influence of the slope angle [30] and vector height of arch HFCCT [31] on earth pressure has been studied. The above studies found that the cross section type of high-filled structure has a certain influence on earth pressure distribution around it.

For culverts, studies have assessed load reduction and section shapes; however, for HFCCT, studies were intensively focused on load reduction and their influence on earth pressure with different section types [31]. There are no systematic studies on optimal coupling of load reduction in HFCCT. Therefore, we considered the discreteness, inhomogeneity, and interactions of soil in the backfill soilstructure. Combined effects of optimal cross section type and load reduction material characteristics (density and laying position of EPS; width and height of concrete wedges $(\mathrm{CW})$ ) were studied. Three load reduction measures were compared: cross section types of HFCCT, combination of optimized cross section type with load reduction using EPS, and combination of optimized cross section type with optimized load reduction using EPS and CW. The effects of different cross section types and characteristics of load reduction materials on earth pressure distribution above HFCCT were analyzed using the PFC2D software. The optimal values for load reduction effects under the three kinds of load reduction measures were determined.

\section{Numerical Simulations}

The numerical test for load reduction in HFCCT was conducted using the commercial calculation software PFC2D (Particle Flow Code in 2D, Itasca 2016) developed by Itasca [32]. The PFC2D model consists of many disks and contact point interactions [33], which are used to calculate particle forces and displacements with two continuous cycles.

2.1. Model Establishment. The HFCCT model was established through the similarity ratio of 1/25 according to the laboratory model test of $\mathrm{Ma}$ et al. [30]. Earth pressure, vertical displacement (VD), and microcontact of soil particles were evaluated by changing different influencing factors (cross section types, density and laying positions of EPS, as well as CW height and width). To assess the influence of cross section types on earth pressure around the HFCCT, we defined the concept of cross section optimization coefficient, that was, the ratio of arch height to width of HFCCT, expressed as an alphabet $\lambda$. A total of five test schemes were designed. Specific experimental schemes and model sizes are shown in Table 1 and Figure 1, respectively.

The numerical model establishment processes in the working conditions shown in Table 1 were similar; therefore, the modeling process of the case $\mathrm{C} 5$ was given a minute description. Figure 1 shows that the ball particle was arranged to simulate the backfill soil. Two different models were selected for contact models between particles used in the PFC2D model: the linear model was used for contact between EPS particles and the linear contact bond model was selected to simulate contact characteristics for cohesive soil particles (loess). Boundary conditions (slope, HFCCT, and foundation) were simulated using wall elements. Total height of the model was $1.3 \mathrm{~m}$, which included a backfill height of $1.2 \mathrm{~m}$ and an unfilled height of $0.1 \mathrm{~m}$. The width of the foundation $(D=0.6 \mathrm{~m})$, the width of HFCCT $(S=0.2 \mathrm{~m})$, the slope angle $\left(\beta=70^{\circ}\right)$, and the two CWs extending from the bottom of the slope to the top for the requirements were set. The backfill was layered by the IMCM method, and the thickness of each layer was $0.2 \mathrm{~m}$.

To assess vertical earth pressure (VEP) above the HFCCT, lateral earth pressure (LEP) on the sides of the HFCCT, VD, porosity and coordination number of soil particles, a number of measurement circles, and displacement monitoring points were arranged in the model. The diameter of these measurement circles was 10 times the size of soil particles $(6 \mathrm{~mm})$, and their locations are as shown in Figure 2. Measurement circles from numbers 1 to 9 were used to measure VEP above the HFCCT, measurement circles numbered 3 to 7 were used to calculate the average VEP, while numbers 5 to 7 measurement circles were used to measure porosity and coordination number of soil particles above the HFCCT. Numbers 10 to 18 measurement circles were used to measure VD of soil particles above the HFCCT and the VEP of backfill soil between the two concrete wedges; measurement circles numbered 14 and 12 (or 14 and 16) were used to calculate relative vertical displacements (RVD) of soil particles above the HFCCT; measurement circles numbered 5,14 , and 23 to 28 were used to measure VEP at different backfill depths above HFCCT; and measurement circles numbered 19 to 22 were used to measure VEP above the CWs, while those numbered $a$ to $j$ (or $a^{\prime}$ to $j^{\prime}$ ) were used to measure LEP on both sides of HFCCT.

\subsection{Material Parameters}

2.2.1. Loess. Macroscopic loess parameters were defined as described by Li et al. [34] (Table 2). The biaxial test model was established through repeated measurements and debugging. The model size had a width of $0.5 \mathrm{~m}$ and a height of $1.0 \mathrm{~m}$ (Figure 3). Parameter calibration processes 
TABle 1: Test schemes design.

\begin{tabular}{lccccc}
\hline Cases & The parameters & \multicolumn{3}{c}{ Working conditions } \\
\hline C1 & Cross section optimization coefficient & 0 (rectangle) & 0.4 & 0.7 & 1.0 \\
C2 & EPS density $\left(\mathrm{kg} / \mathrm{m}^{3}\right)$ & 12 & 15 & 20 & 30 \\
C3 & EPS laying position $(\mathrm{m})$ & 0 & 0.02 & 0.05 & 0.08 \\
C4 & Concrete wedges height $(\mathrm{m})$ & 0.20 & 0.26 & 0.32 & 0.38 \\
C5 & Concrete wedges width $(\mathrm{m})$ & 0.12 & 0.17 & 0.22 & - \\
\hline
\end{tabular}

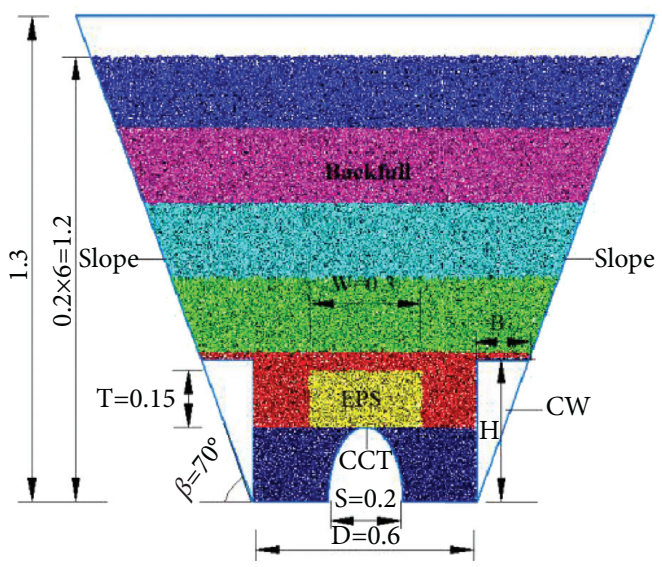

FIgURE 1: HFCCT model diagram of PFC2D (unit: $m$ ).

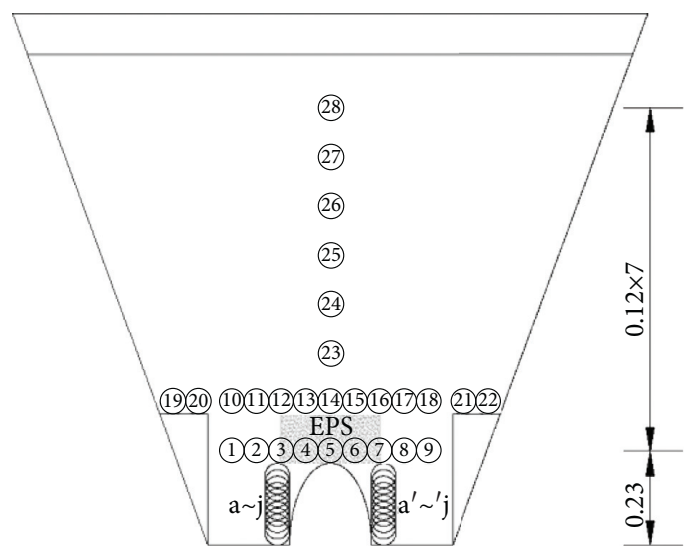

Figure 2: Arrangement for measuring points (unit: m).

TABle 2: Macroscopic parameters of loess.

\begin{tabular}{ccccccc}
\hline & Relative compaction (\%) & Young's modulus $(\mathrm{MPa})$ & Poisson's ratio & Cohesion $(\mathrm{kPa})$ & Cohesion $(\mathrm{kPa})$ & Unit weight $\left(\mathrm{kN} / \mathrm{m}^{3}\right)$ \\
\hline Loess & 85 & 5.4 & 0.3 & 31.11 & 28.24 & 17.7 \\
\hline
\end{tabular}

were as follows: First, the ball distribute command in PFC2D was used to balance uneven particle forces within the model. Particles reached the initial equilibrium, while the uneven force reached the set value (1E-3) in the command flow. Then, particles in the model were subjected to constant pressure consolidation and axial loading by the servo control mechanism until shear failure occurred, and simulation results of loess parameters were obtained. The microscopic parameters used in the numerical model are shown in Figure 4(a). Simulation results are shown in Table 3.
2.2.2. Expanded Polystyrene. Simulation of EPS was done by a disk particle element in the contact constitutive model; the distribution range of particle sizes was from 6 to $10 \mathrm{~cm}$, following a standard normal curve distribution. Since earth pressure around HFCCT was far from reaching the corresponding strength of EPS when it was yielding (5\%), the stress-strain curve of EPS within 5\% was selected as the microscopic parameter for calibration [35]. Its microparameter calibration process was similar to that of loess. However, the difference was in selection of the contact constitutive model and compression method; that is, the 


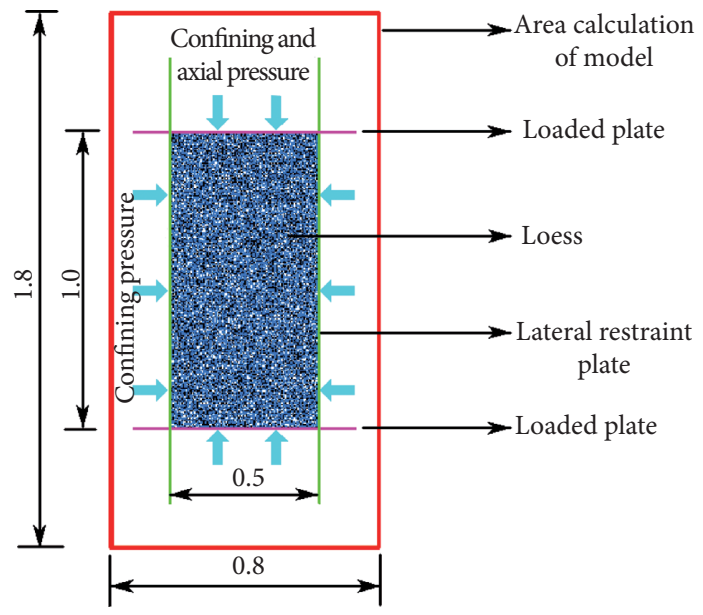

Figure 3: Dimensions of the biaxial test model (unit: $\mathrm{m}$ ).
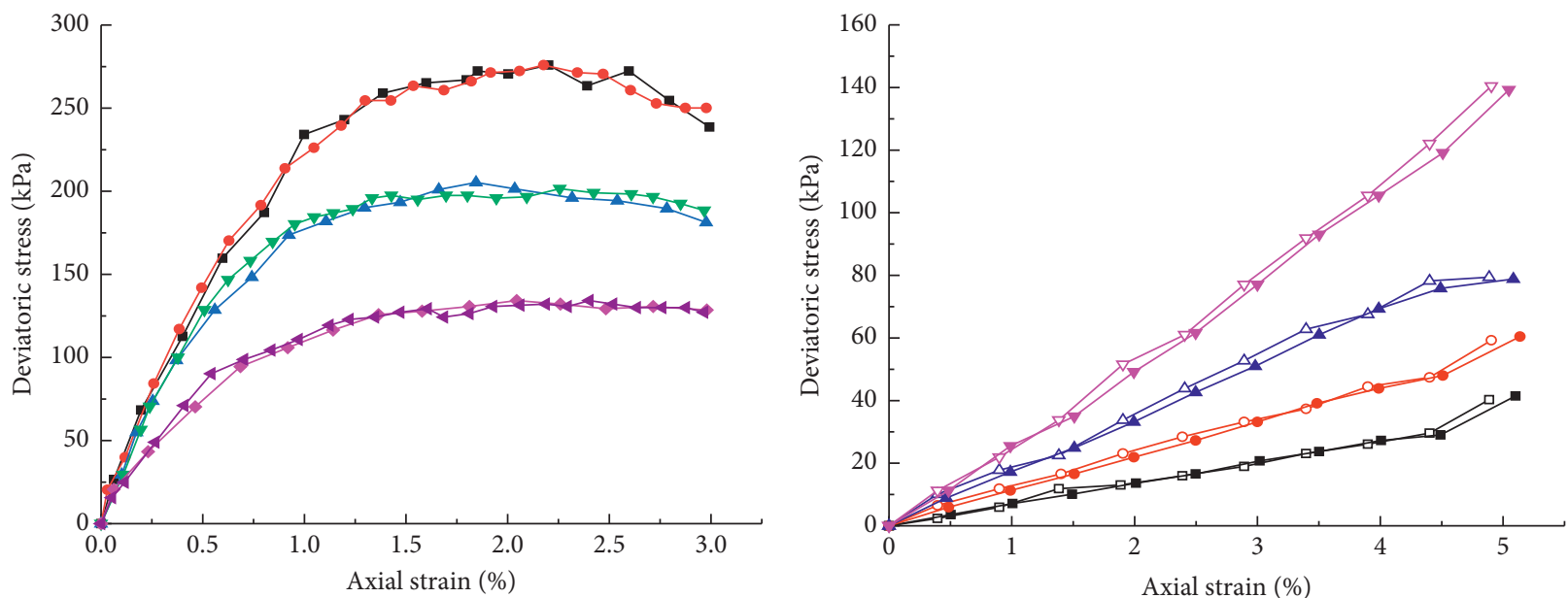

$\begin{array}{ll}\text { Experimental result } & \text { DEM result } \\ \rightarrow 50 \mathrm{kPa} & \rightarrow-50 \mathrm{kPa} \\ \rightarrow 75 \mathrm{kPa} & \rightarrow-75 \mathrm{kPa} \\ \leftarrow 100 \mathrm{kPa} & \rightarrow-100 \mathrm{kPa}\end{array}$

(a)

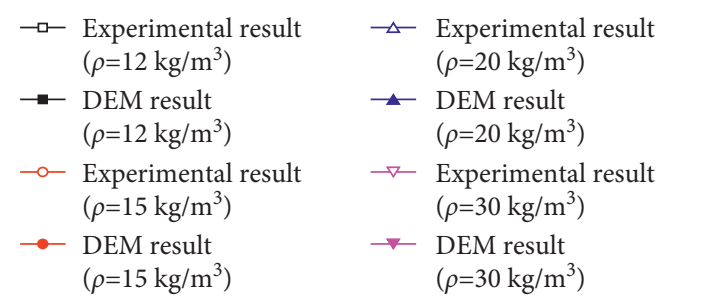

(b)

Figure 4: Comparison of the discrete element method and experimental results for materials: (a) backfill soil; (b) expanded polystyrene.

TABLe 3: Microscopic parameters of the materials.

\begin{tabular}{|c|c|c|c|c|c|c|c|c|}
\hline Parameter & $\begin{array}{c}\text { Diameter of } \\
\text { particles }(\mathrm{mm})\end{array}$ & $\begin{array}{l}\text { Density } \\
\left(\mathrm{kg} / \mathrm{m}^{3}\right)\end{array}$ & $\begin{array}{c}\text { Normal } \\
\text { stiffness } \\
(\mathrm{N} / \mathrm{m})\end{array}$ & $\begin{array}{c}\text { Shear } \\
\text { stiffness } \\
(\mathrm{N} / \mathrm{m})\end{array}$ & $\begin{array}{l}\text { Normal bond } \\
\text { strength }(\mathrm{N})\end{array}$ & $\begin{array}{l}\text { Tangential bond } \\
\text { strength }(\mathrm{N})\end{array}$ & $\begin{array}{l}\text { Coefficient of } \\
\text { friction }\end{array}$ & $\begin{array}{l}\text { Damping } \\
\text { factor }\end{array}$ \\
\hline \multirow[t]{2}{*}{ Loess } & & 1800 & $2 \mathrm{e} 7$ & $1 e 7$ & \multirow[t]{2}{*}{250} & \multirow[t]{2}{*}{250} & 0.6 & \multirow[t]{2}{*}{0.7} \\
\hline & & 12 & $3 \mathrm{e} 6$ & $2 e 6$ & & & 0.15 & \\
\hline \multirow{3}{*}{ EPS } & 6 to 10 & 15 & $3 e 6$ & $2.5 e 6$ & \multirow{3}{*}{ - } & \multirow{3}{*}{-} & 0.27 & \multirow{3}{*}{-} \\
\hline & & 20 & $4 \mathrm{e} 6$ & $3.5 e 6$ & & & 0.32 & \\
\hline & & 30 & $6 e 6$ & $6 e 6$ & & & 0.60 & \\
\hline
\end{tabular}


linear contact model was taken as its constitutive model relation and uniaxial compression was adopted for compression. Comparison results of stress-strain curves of numerical simulation and test are shown in Figure 4(b). The stress-strain curve of the laboratory test was consistent with the stress-strain curve of numerical simulation; therefore, the calibrated EPS parameter results in Table 3 are correct.

\section{Optimization Result Analysis}

3.1. Effects of Cross Section Type. Taking the five cross section shapes in case $\mathrm{C} 1$ as research objects, the earth pressure distribution, displacement, and microscopic contact were evaluated, and cross section shapes of HFCCT were optimized.

\subsubsection{Earth Pressure Distribution. Figure 5 shows earth} pressure distribution for case C1. As shown in Figure 5(a), due to differences in stiffness between HFCCT and backfill soil, analogous VEP distribution occurred on the top, and a $\mathrm{V}$-shaped distribution along the central axis of HFCCT, when cross section types changed from $\lambda=0.4, \lambda=0.7$, $\lambda=1.0$ to circle. Earth pressure concentrated on top of HFCCT decreased outwardly. That is, the more the VEP is concentrated on the HFCCT axis, the faster the decrease rate will be as the distance from the HFCCT axis increases. However, due to right-angle mutations of the rectangular cross section, the soil at the boundary of internal and external soil column subsided, and downward friction of the external soil column was transferred to the internal soil column, resulting in a greater concentration of VEP at the two sides of HFCCT and reduced VEP at the center, exhibiting an M-shaped distribution. In short, the VEP at the top of the HFCCT decreased according to $\lambda=1.0$, circle, $\lambda=0.7$, and $\lambda=0.4$, and rectangle, beyond this range (the width of the HFCCT); it successively decreased in the order of $\lambda=0.4, \lambda=0.7$, circle, rectangle, and $\lambda=1.0$.

Figure 5(b) shows LEP distribution on the sides of HFCCT for case C1. The LEP can be divided into three stages along the HFCCT height: stabilization (stage 1), increase (stage 2), and decrease (stage 3). The LEP remained unchanged as the HFCCT height increased for stage 1 and gradually decreased in order of rectangular, $\lambda=0.4, \lambda=0.7$, $\lambda=1.0$, and circle. Within the stage 2 range, LEP increased with increasing HFCCT height. In stage 3, LEP decreased with HFCCT height. The decrease in LEP was in a sequence of circle, $\lambda=1.0, \lambda=0.7, \lambda=0.4$, and rectangular. The difference is that for cross section of the circle, LEP reached its maximum value at 0.8 times the height of HFCCT when cross section optimization coefficient of $\lambda=0.4,0.7,1.0$, while for the rectangular cross section, LEP reached its maximum value at 0.6 times the height of HFCCT.

Based on the above analysis of VEP and LEP, the difference in earth pressure distribution of HFCCT with different sections was not obvious. Therefore, a method, equivalent load method, for determining optimal section type of HFCCT by calculating the average earth pressure was proposed. The calculated average earth pressure of HFCCT for case $\mathrm{C} 1$ is shown in Figure 6. The average VEP on top of HFCCT decreased first and then increased, reaching its minimum value of $17.89 \mathrm{kPa}$ at $\lambda=1.0$ and its maximum value of $20.37 \mathrm{kPa}$ at the rectangular cross section. However, average LEP was inversely proportional to average VEP; the maximum value of $8.65 \mathrm{kPa}$ and the minimum value of $7.26 \mathrm{kPa}$ were located at $\lambda=1.0$ for the rectangular cross section, respectively. In conclusion, the earth pressure exerted on HFCCT was the most unfavorable when the cross section was rectangular and most favorable at optimal cross section optimization coefficient of $\lambda=1.0$. Therefore, optimal cross section optimization coefficient of $\lambda=1.0$ can be considered as the optimal cross section optimization coefficient for HFCCT without load reduction.

3.1.2. Variation of Displacement. Figure 7 shows the VD distribution of soil particles for case C1. The VD of soil particles symmetrically increased with increasing distance from the HFCCT axis, presenting an inverted V-shaped distribution. As the cross section shape changed, the VD of soil particles increased with cross section optimization coefficient of $\lambda$ ranging from $0.4,0.7$, to 1.0 . This is because, the larger $\lambda$, the sharper the arching tendency of HFCCT, and the easier it is for soil particles to slide downward. However, the VD of soil particles was relatively small at the HFCCT axis and increased sharply at two sides of HFCCT when the cross section type was rectangular and circular. Moreover, the growth rate of VD was larger than those of the other HFCCT sections.

Figure 8 shows the RVD and height of the equal settlement plane of soil particles for case C1. The RVD of soil particles was proportional to the height of equal settlement plane, which decreased first and then increased. Gradually, they both decreased as the type of cross section changed from rectangular to cross section optimization coefficient $\lambda=1.0$; however, they gradually increased when the type changed from $\lambda=1.0$ to circle and reached the minimum value of $0.024 \mathrm{~mm}$ and $0.582 \mathrm{~m}$ at cross section optimization coefficient of $\lambda=1.0$, respectively.

The nephograms on VD of soil particles for case $\mathrm{C} 1$ are shown in Figure 9. Figures 9(a)-9(d) show that the VD of soil particles on top of HFCCT was smaller than that on the sides of HFCCT. This is attributed to differences in stiffness of HFCCT and backfill soil. However, with increasing backfill height, the VD of soil particles changed slowly, while the RVD decreased gradually until there was a plane of equal settlement (see the black line in the figure). By comparing with different cross section types of HFCCT, the equal settlement plane decreased gradually as cross section type changed from rectangular to $\lambda=1.0$ and started to increase when cross section type changed from $\lambda=1.0$ to circle, consistent with variation results of RVD in Figure 8.

Based on the relationship of VEP, RVD, and height of equal settlement plane, in the absence of load reduction, the smaller the RVD of the external soil column and internal soil column, the lower the height of the equal settlement plane, which led to downward friction of the external soil column that was transferred to the internal soil column to be smaller, 


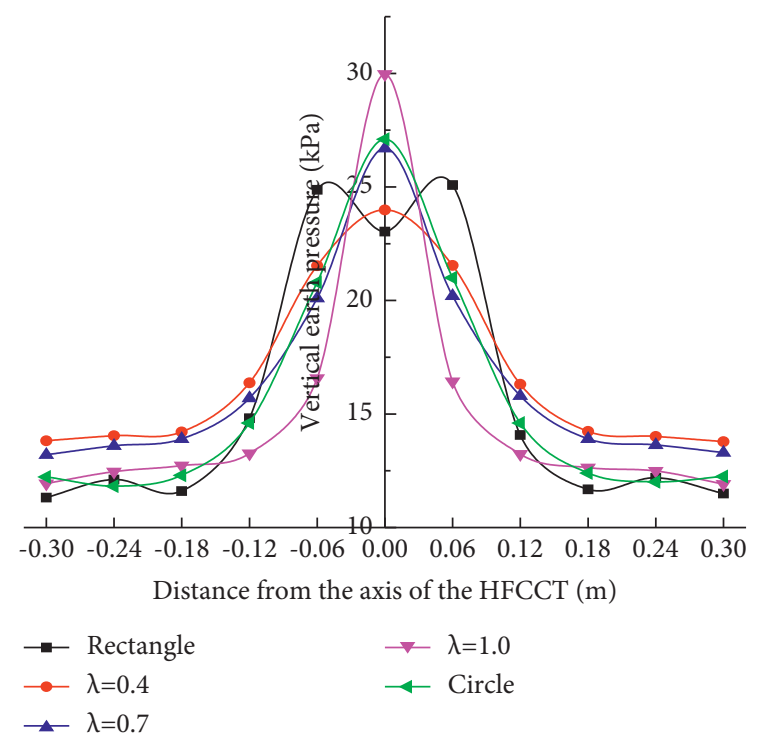

(a)

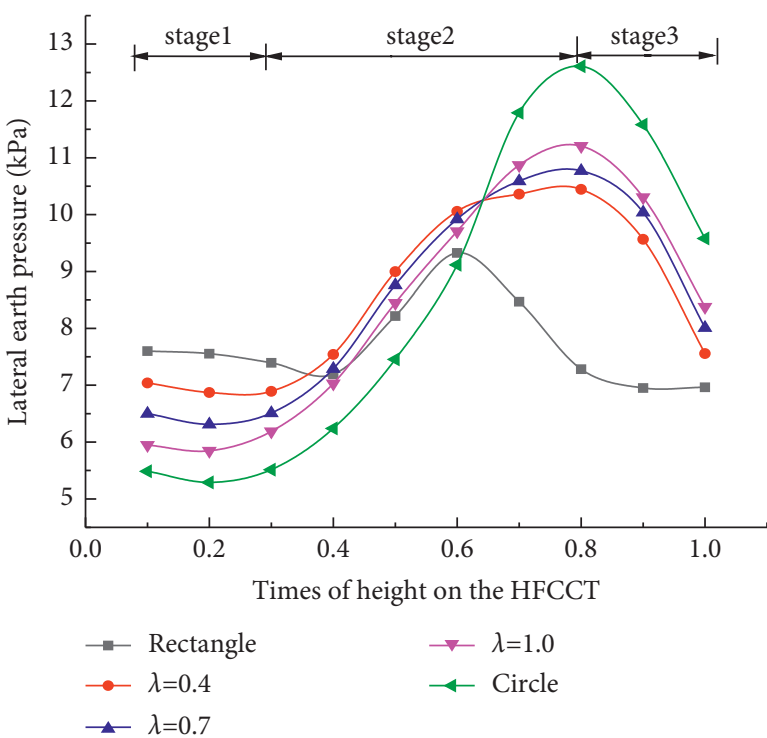

(b)

FIGURE 5: Earth pressure distribution for case C1: (a) VEP; (b) LEP.

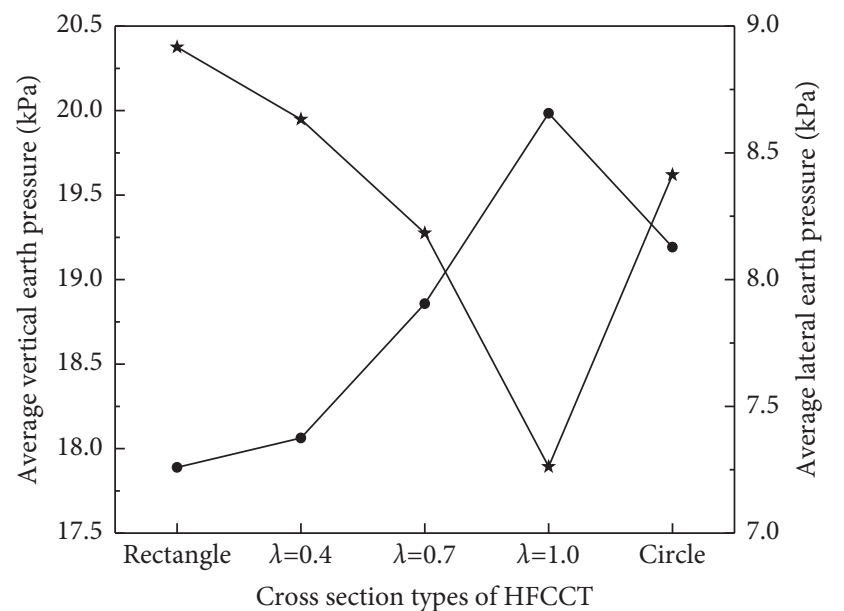

$\star$ Average vertical earth pressure

- Average lateral earth pressure

Figure 6: Average earth pressure distribution for case C1.

making the VEP to be smaller. Therefore, VEP, RVD, and height of the equal settlement plane presented the minimum value at the cross section optimization coefficient of $\lambda=1.0$.

3.1.3. Variation of Microscopic Contact. To investigate load distribution and transfer mechanism of soil particles around HFCCT for case C1, we evaluated various factors at the microscopic level, such as porosity, coordination number, and contact force chain.

Figure 10 shows the relationship between porosity and coordination number for case C1. Porosity was inversely proportional to coordination number. The maximum value (0.155) of porosity and the minimum value (3.82) of coordination number simultaneously appeared when section

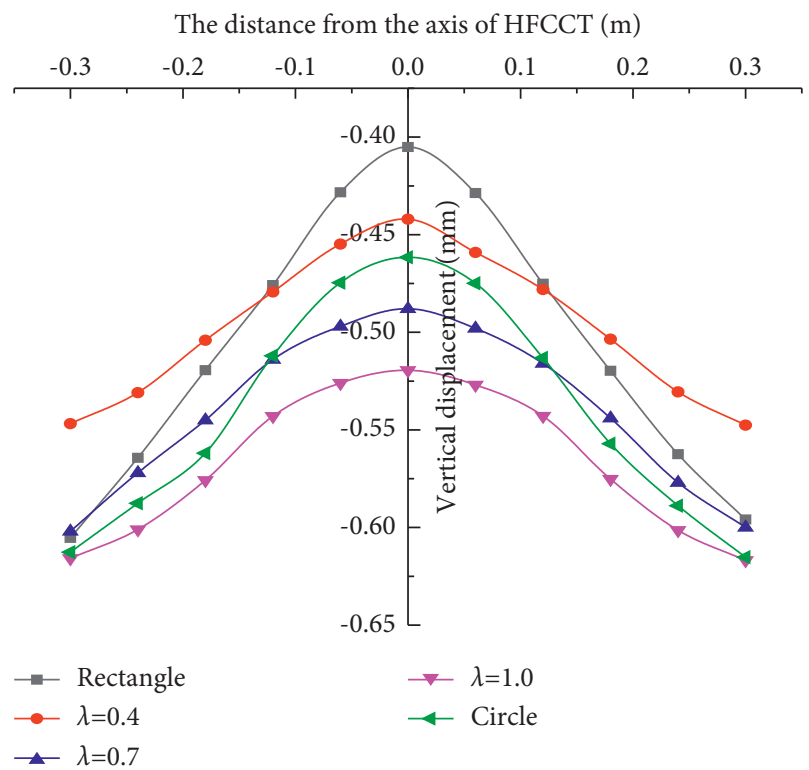

Figure 7: Vertical displacement of soil particles for case C1.

optimization coefficient $\lambda$ was 1.0. Combined with Figure 5(b), it is determined that the larger the porosity, the larger the LEP, but the smaller the coordination number of soil particles, the smaller the VEP on top of HFCCT and RVD among soil particles.

Figure 11 shows the relationship between contact force chain of soil particles and cross sectional shape of HFCCT. As the cross section type of HFCCT changed from rectangular to $\lambda=1.0$, contact force chains on top of HFCCT became sparse (see the area enclosed by the green arc in the figure); due to large impact of soil arching, it was concentrated towards the top of HFCCT (see the green arrow in the figure). However, as the cross section type of HFCCT 


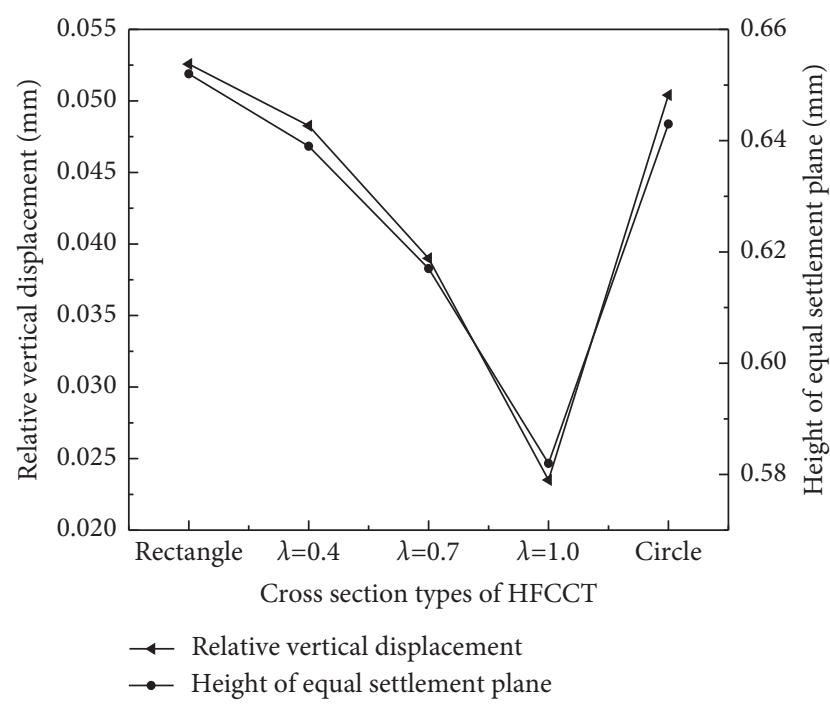

FIGURE 8: Relative vertical displacements and the height of equal settlement plane of soil particles for case $\mathrm{C} 1$.

changed from $\lambda=1.0$ to circular, contact force chains became denser and VEP on top of HFCCT correspondingly increased. The variation was consistent with results of earth pressure in Figure 6, indicating that cross section optimization coefficient of $\lambda=1.0$ can be considered as the optimal cross section optimization coefficient among the HFCCT sections.

3.2. Effects of Expanded Polystyrene. In this section, the EPS load reduction model of HFCCT was established with the same size and cross section optimization coefficient $\lambda=1.0$ on the basis of the above HFCCT. Effects of EPS characteristics (density and laying position) on load reduction on HFCCT were analyzed. Regarding EPS characteristics, the most favorable values of thickness and width were selected [15], which were $0.15 \mathrm{~m}$ and $0.3 \mathrm{~m}$, respectively.

3.2.1. Influence of Expanded Polystyrene Density. To assess the effects of EPS density on earth pressure, the influence of density variations from $12 \mathrm{~kg} / \mathrm{m}^{3}$ to $30 \mathrm{~kg} / \mathrm{m}^{3}$ on earth pressure, $\mathrm{VD}$, and microscopic contact of soil particles was determined.

(1) Earth Pressure Distribution. Figure 12(a) shows VEP distribution on top of HFCCT for case C2, VEP on top of HFCCT was distributed in a $U$ shape along the HFCCT central axis, and the maximum value was reached when distance from the HFCCT axis was $0.18 \mathrm{~m}$. As the EPS density changed, VEP decreased as densities changed from $30 \mathrm{~kg} / \mathrm{m}^{3}, 20 \mathrm{~kg} / \mathrm{m}^{3}$, and $12 \mathrm{~kg} / \mathrm{m}^{3}$, to $15 \mathrm{~kg} / \mathrm{m}^{3}$ in the range of $0.15 \mathrm{~m}$ from the HFCCT axis. Beyond that range $(0.15 \mathrm{~m}$ from the HFCCT axis), VEP exhibited the opposite pattern. Figure 12(b) shows LEP distribution of HFCCT for case C2. Within the range of 0.1 to 0.7 times height of HFCCT, LEP decreased from $12 \mathrm{~kg} / \mathrm{m}^{3}, 15 \mathrm{~kg} / \mathrm{m}^{3}, 20 \mathrm{~kg} / \mathrm{m}^{3}$, to $30 \mathrm{~kg} / \mathrm{m}^{3}$, while LEP values were reversed in the range of 0.7 to 1.0 times height of HFCCT. Based on these results, changes in VEP and LEP were basically opposite.

Figure 13 shows the average earth pressure of HFCCT for case $\mathrm{C} 2$. The average VEP was inversely proportional to average LEP, reaching its minimum value $(5.2 \mathrm{kPa})$ and maximum value $(10.4 \mathrm{kPa})$ at the density of $\rho=15 \mathrm{~kg} / \mathrm{m}^{3}$, respectively. Therefore, $15 \mathrm{~kg} / \mathrm{m}^{3}$ can be regarded as the optimal density.

(2) Variation of Displacement. Figure 14 shows the VD distribution of soil particles for case C2. The VD of soil particles was distributed in a V shape. This is because EPS has a large compression deformation characteristic, which makes settlement of internal soil column to be greater than that of external soil column, resulting in negative settlement differences. The VD of soil particles changed with EPS density, which was sequentially decreased based on EPS densities of $15 \mathrm{~kg} / \mathrm{m}^{3}, 12 \mathrm{~kg} / \mathrm{m}^{3}, 20 \mathrm{~kg} / \mathrm{m}^{3}$, and $30 \mathrm{~kg} / \mathrm{m}^{3}$. When the density of $\rho$ was $15 \mathrm{~kg} / \mathrm{m}^{3}$, the settlement difference and RVD between the internal and external soil column was largest while the VEP on top of HFCCT was least when the density of $\rho=15 \mathrm{~kg} / \mathrm{m}^{3}$. Earth pressure distribution was most reasonable at this density.

\subsubsection{Influence of Expanded Polystyrene Laying Position.} When the EPS laying position changed from $0 \mathrm{~m}$ to $0.08 \mathrm{~m}$ on top of HFCCT, the earth pressure, VD, and microcontact of soil particles were evaluated.

(1) Earth Pressure Distribution. The influence of different laying positions on VEP distribution is shown in Figure 15(a). The VEP on top of HFCCT was distributed in a $U$ shape along the HFCCT central axis. As the EPS laying position increased from $0 \mathrm{~m}$ to $0.05 \mathrm{~m}$, the VEP on top of HFCCT did not exhibit a significant change. However, as the EPS laying position was further increased (e.g., $L=0.08 \mathrm{~m}$ ), VEP on top of HFCCT increased significantly, and the load reduction effect disappeared. Distribution of LEP with different EPS laying positions is shown in Figure 15(b). It is shown that LEP decreased with increasing EPS laying position, which occurred in a descending order: $0 \mathrm{~m}, 0.02 \mathrm{~m}$, $0.05 \mathrm{~m}$, and $0.08 \mathrm{~m}$.

Variations in average earth pressure for case C3 are presented in Figure 16. With the increase in EPS laying position, the average VEP increased while the average LEP decreased. From the earth pressure distribution perspective, this implies that the further the EPS laying position, the greater the VEP on the top and the smaller the LEP, which means that the load on HFCCT was unfavorable.

(2) Variation of Displacement. Figure 17 shows the VD distribution of soil particles for case C3. The settlement difference in the internal soil column was greater than that of the external soil column, while the VD of soil particles decreased with increasing distance from the HFCCT axis, when the EPS laying position was within the $0.05 \mathrm{~m}$ range. However, as the EPS laying position increased further, the $\mathrm{VD}$ of soil particles gradually decreased, reaching its 
Ball Extent displacement_y

Balls Extents (5764)
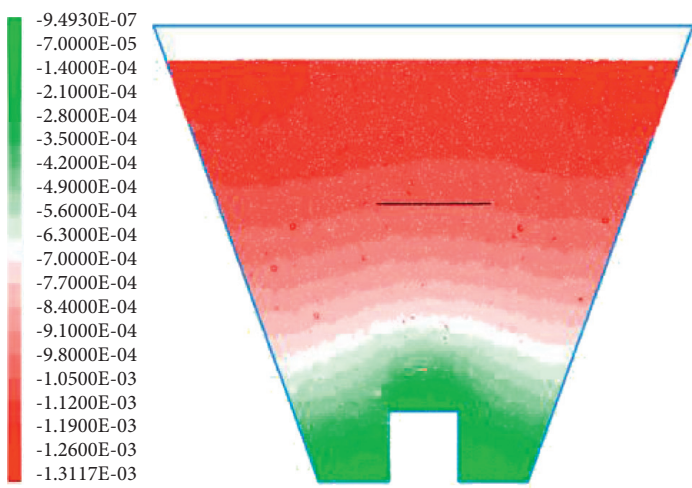

(a)

Ball Extent displacement_y

Balls Extents (5773)
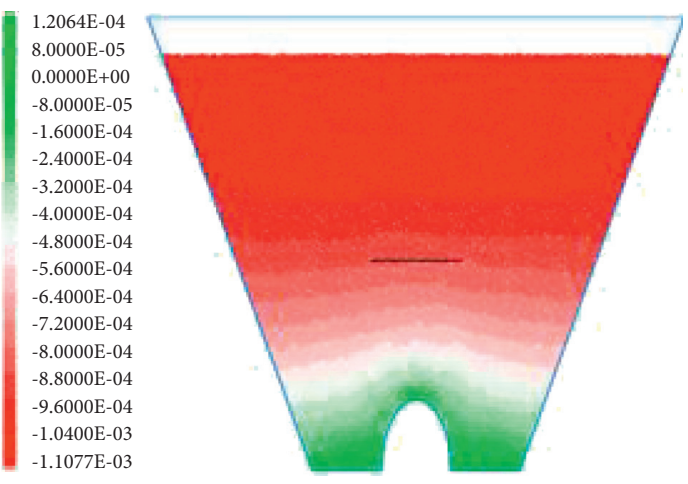

(c)
Ball Extent displacement_y

Balls Extents (5775)
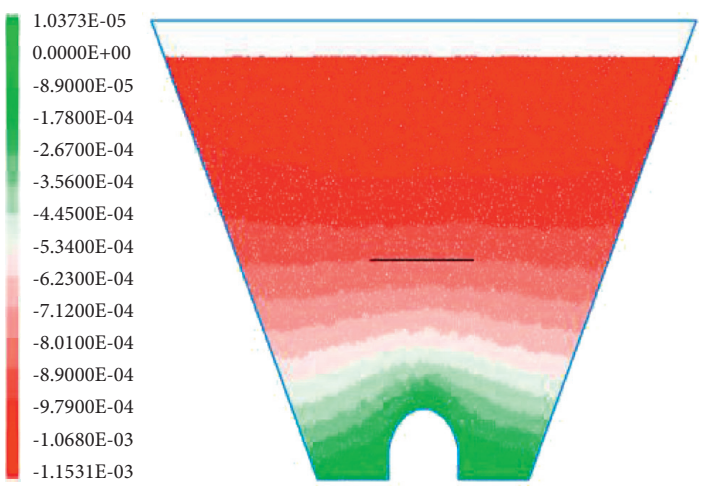

(b)

Ball Extent displacement_y Balls Extents (5775)
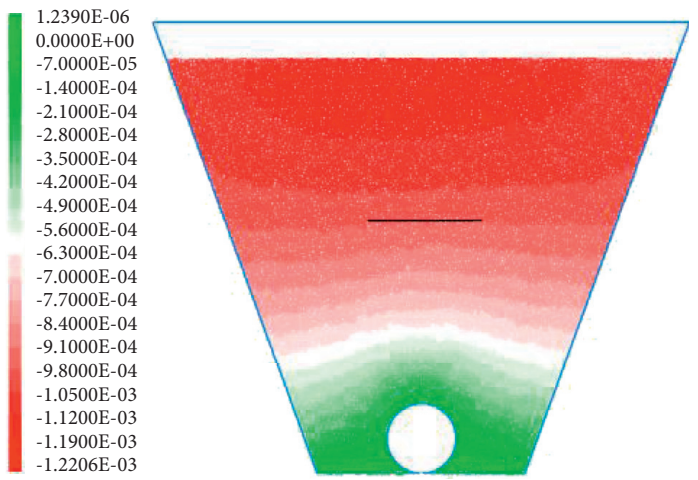

(d)

Figure 9: Vertical displacement nephograms of soil particles for case C1: (a) rectangle; (b) $\lambda=0.7$; (c) $\lambda=1.0$; (d) circle.

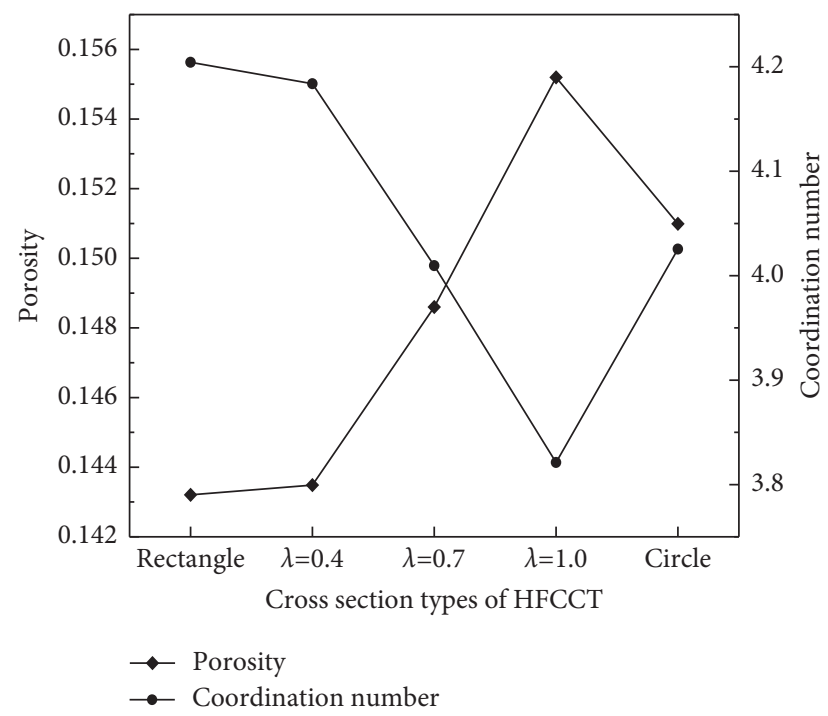

FIGURE 10: Porosity and coordination number of soil particles for case $\mathrm{C} 1$.

minimum value at the laying position of $0.08 \mathrm{~m}$, implying that the VD of soil particles at the HFCCT axis was smaller than that on both sides of HFCCT. Moreover, EPS had no load reduction effects on earth pressure on top of HFCCT, consistent with results shown in Figure 15(a).

Figure 18 shows the VD nephograms of soil particles for case C3. Due to laying of EPS, the VD of soil particles on top of HFCCT severely sunk, when compared to the VD on both sides of HFCCT. This is because of the huge deformation of EPS. Furthermore, with increasing EPS laying position, load reduction effect of EPS was away from the top of HFCCT (see the height of $h$ in Figure 18).

(3) Variation of Microscopic Contact. Figure 19 shows contact force chains of soil particles for case C3. Earth pressure distribution was significantly changed through its own compressibility, which transferred the load from the top of HFCCT to the sides of HFCCT. As a result, contact force chains were mainly distributed on side walls and foundations of HFCCT, and the distribution of contact force chains on top of HFCCT was significantly reduced due to soil arching effect formed by EPS (see the red circle in the figure). With increasing EPS laying position, contact force chain was denser and earth pressure was larger on both sides of HFCCT. However, the soil arching effect did not change (see the red circle in the figure). Moreover, the load in the area that was immediately adjacent to the top of HFCCT 


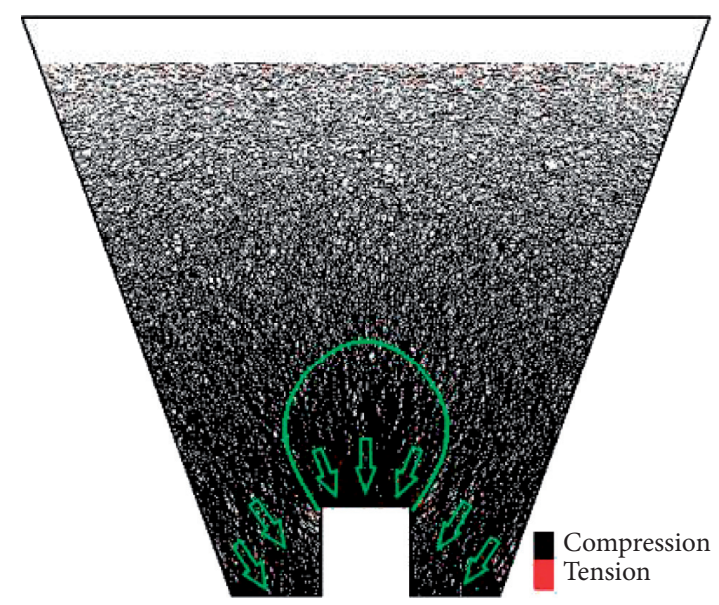

(a)

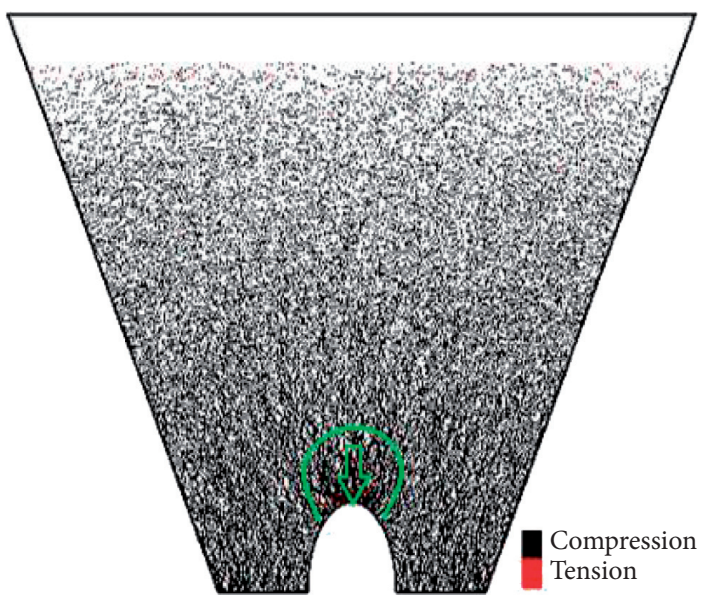

(c)

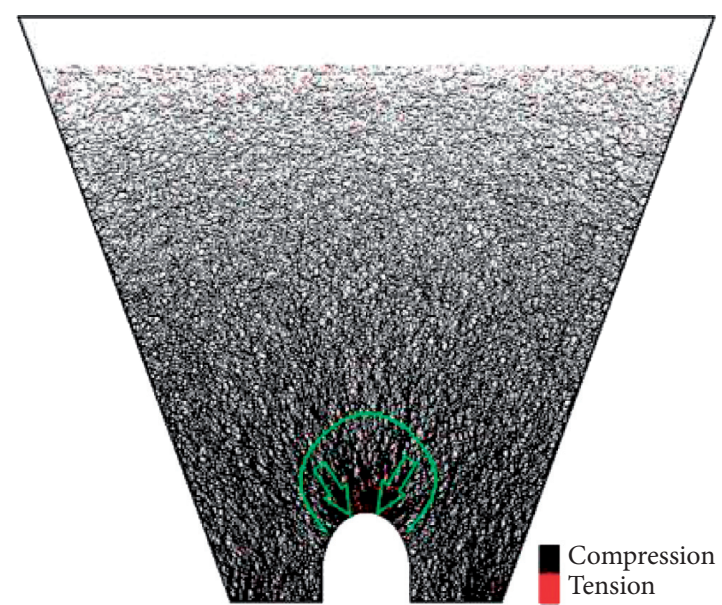

(b)

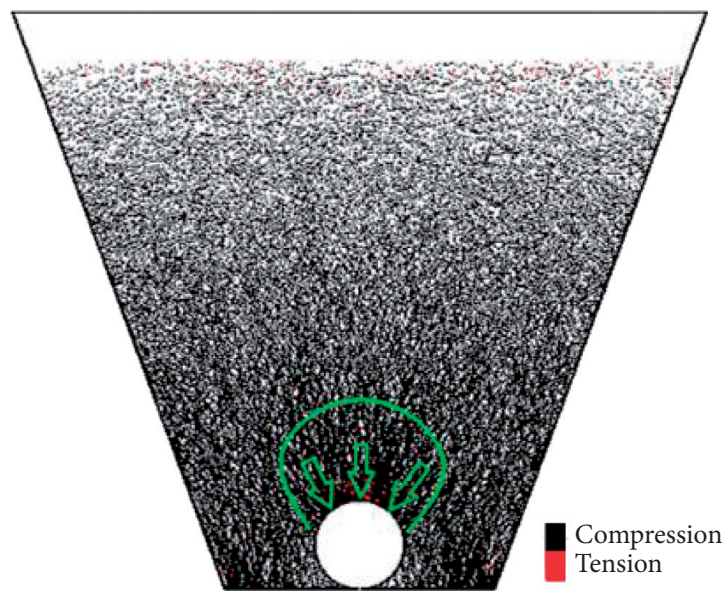

(d)

FIGURE 11: Distribution of contact force chains for case C1: (a) rectangle; (b) $\lambda=0.7$; (c) $\lambda=1.0$; (d) circle.

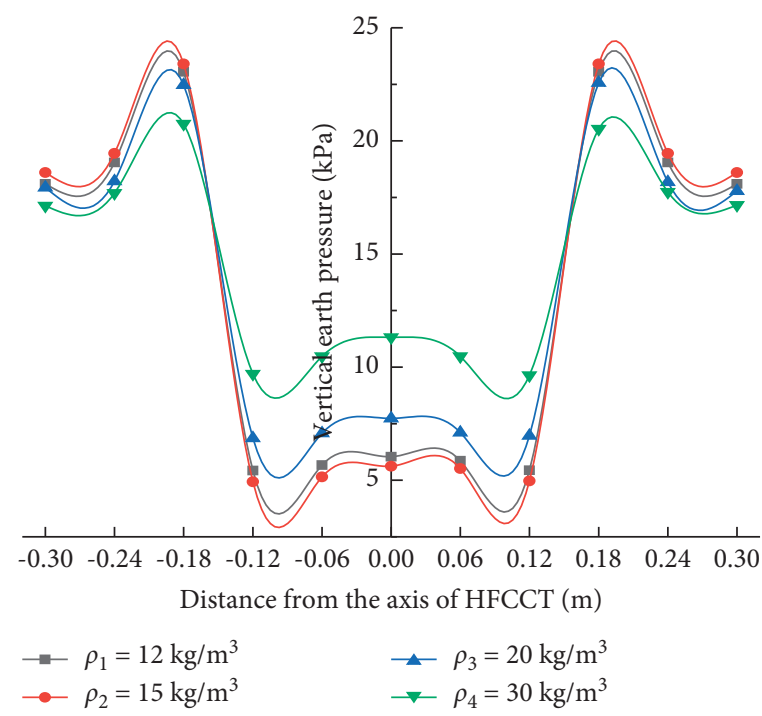

(a)

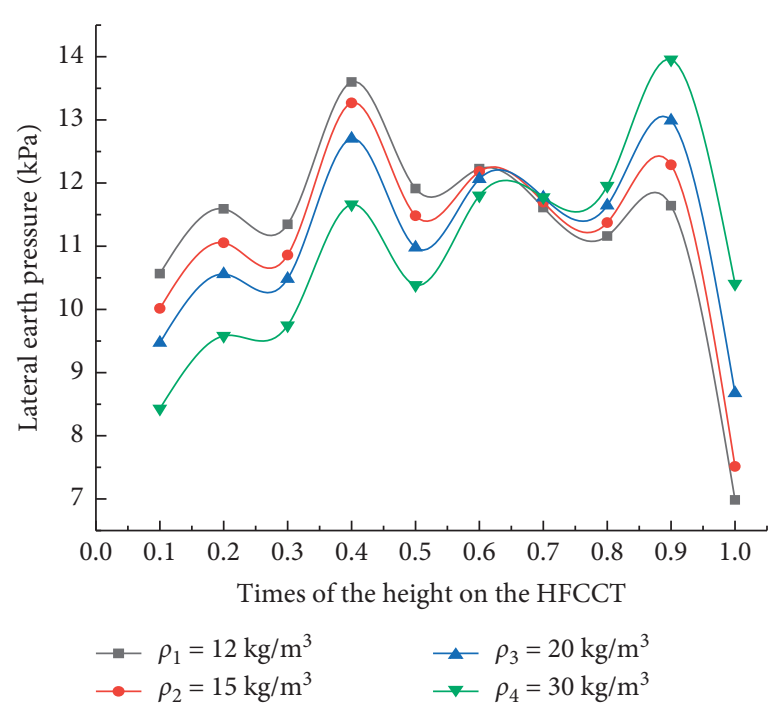

(b)

FIGURE 12: Earth pressure distribution for case C2: (a) VEP; (b) LEP. 


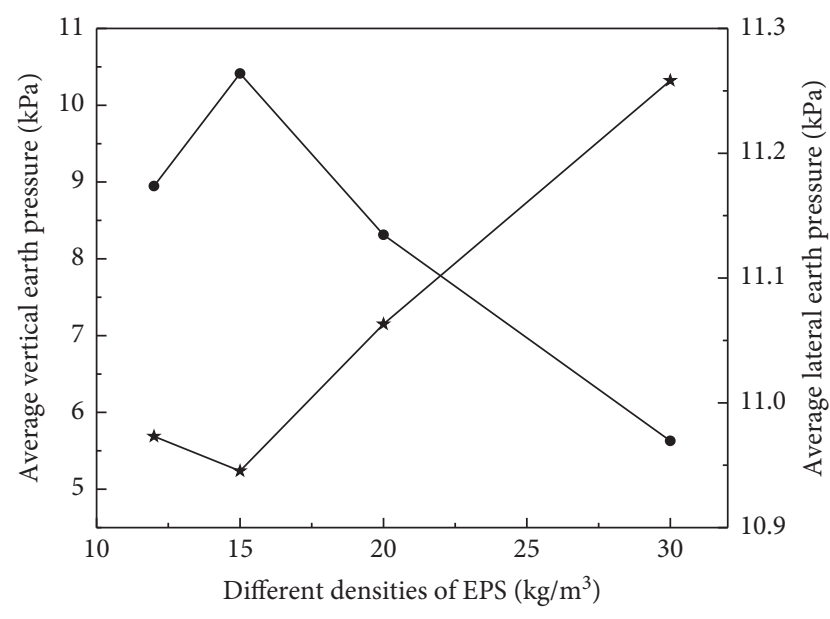

$\star$ Average vertical earth pressure

$\rightarrow$ Average lateral earth pressure

Figure 13: Average earth pressure for case C2.

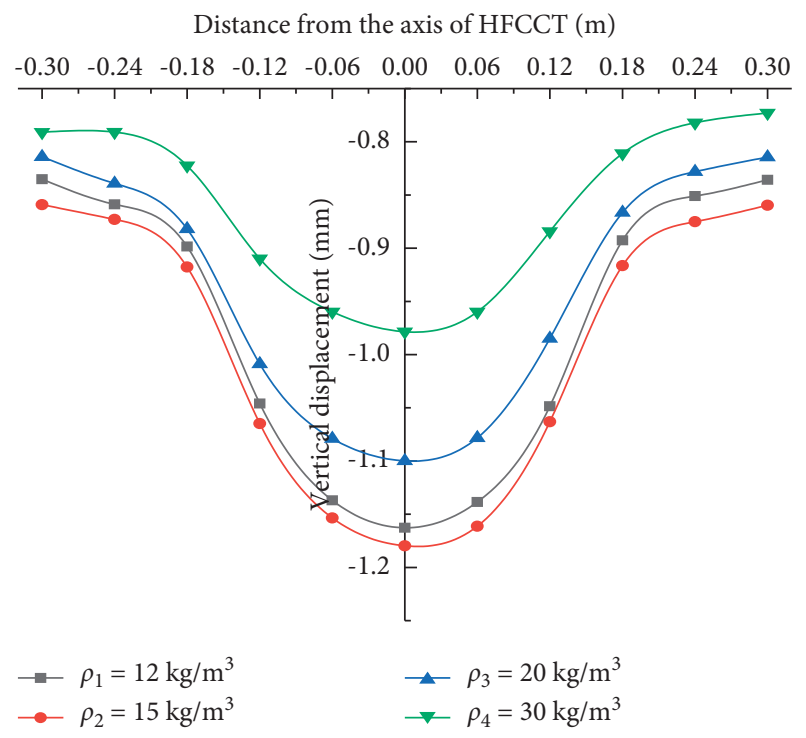

Figure 14: Vertical displacement for case C2.

increased (see the yellow arcs in the figure), resulting in an increase in VEP on top of HFCCT (compared with Figure 16). Therefore, in practical construction, EPS should be laid as close to the top of HFCCT as possible.

3.3. Effects of Concrete Wedges. To reduce load distribution around the HFCCT and improve load reduction efficiency, load reduction measure of the combination of optimized cross section type with load reduction using EPS and CW was evaluated. The width $W=0.3 \mathrm{~m}$, density $\rho=15 \mathrm{~kg} / \mathrm{m}^{3}$, laying thickness $T=0.15 \mathrm{~m}$, laying position $L=0 \mathrm{~m}$ of EPS, and cross section optimization coefficient $\lambda=1.0$ were selected.

3.3.1. Influence of Concrete Wedges Height. To establish the effects of CW height on earth pressure, variations in earth pressure, $\mathrm{VD}$, and microcontact of soil particles were analyzed as CW height changed from $0.20 \mathrm{~m}$ to $0.38 \mathrm{~m}$.

(1) Earth Pressure Distribution. To establish the load reduction effect of CW, the column-soil stress ratio was defined as the average load ratio on top of CW to soil particles between the two CWs. Variations in the column-soil stress ratio and average VEP distribution on top of HFCCT for case C4 are shown in Figure 20. The column-soil stress ratio was inversely proportional to average VEP distribution, presenting the maximum value $(11.2 \mathrm{kPa})$ and minimum value $(3.25 \mathrm{kPa})$ at the CW height of $H=0.32 \mathrm{~m}$. This indicated that a large amount of earth pressure was shared with $\mathrm{CW}$, which reduced the earth pressure around HFCCT at the CW height of $0.32 \mathrm{~m}$.

(2) Variation of Displacement. The influence on RVD and equal settlement plane for case C4 is shown in Figure 21. RVD was approximately the same as the height of equal settlement plane, which increased first and then decreased with increasing $\mathrm{CW}$ height. Both reached their maximum values, $-0.155 \mathrm{~mm}$ and $0.885 \mathrm{~m}$, respectively, at the CW height of $H=0.32 \mathrm{~m}$, indicating that settlement difference between internal soil column and external soil column was obvious at the CW height of $0.32 \mathrm{~m}$.

Figure 22 shows VD nephograms of soil particles for case C4. Due to CW arrangement, the VD of soil particles above $\mathrm{CW}$ was significantly reduced (see the green area in the figure). While the VD of soil particles above HFCCT increased sharply in a certain range of CW height (see Figures 22(a)-22(b)) and then decreased with the increase of the $\mathrm{CW}$ height (see Figure 22(b)-22(c)), which reached the maximum value $(-1.639 \mathrm{~m})$ at the CW height of $0.32 \mathrm{~m}$. Therefore, the CW height of $0.32 \mathrm{~m}$ can be considered optimal.

(3) Variation of Microscopic Contact. Figure 23 shows contact force chains of soil particles for case C4. Contact force chains were mainly distributed above CW. The distribution of contact force chains on top of HFCCT was significantly reduced due to soil arching effects caused by EPS, and the scope of soil arching effect was further expanded (see the blue curve in the figure). Moreover, contact force chains on both sides of HFCCT were denser at CW height of $H=0.20 \mathrm{~m}$ and $0.38 \mathrm{~m}$ than that at CW height of $H=0.32 \mathrm{~m}$, indicating that the load on both sides of HFCCT was smallest at CW height of $H=0.32 \mathrm{~m}$.

3.3.2. Influence of Concrete Wedges Width. Given the influence of CW width on earth pressure on HFCCT, variations in earth pressure, $\mathrm{VD}$, and microcontact of soil particles were analyzed as CW width changed from $0.12 \mathrm{~m}$ to $0.2 \mathrm{~m}$.

(1) Earth Pressure Distribution. Figure 24 shows that the column-soil stress ratio was inversely proportional to average VEP, reaching its maximum value $(12.75 \mathrm{kPa})$ and minimum value $(3.125 \mathrm{kPa})$, respectively, at $\mathrm{CW}$ width of $W=0.17 \mathrm{~m}$. This indicated that CW the most earth pressure and earth pressure above HFCCT decreased the most at CW width of $W=0.17 \mathrm{~m}$. Therefore, earth pressure at $\mathrm{CW}$ width 


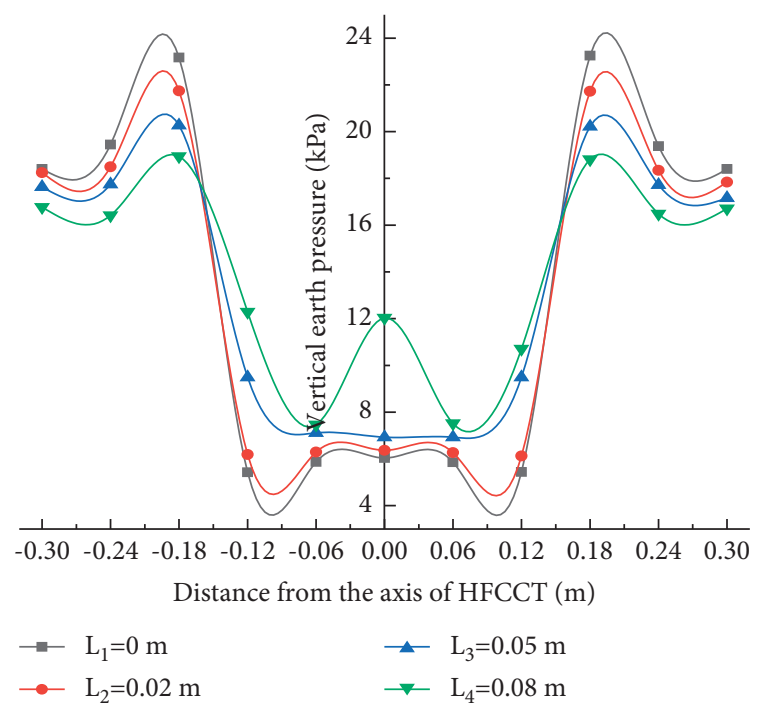

(a)

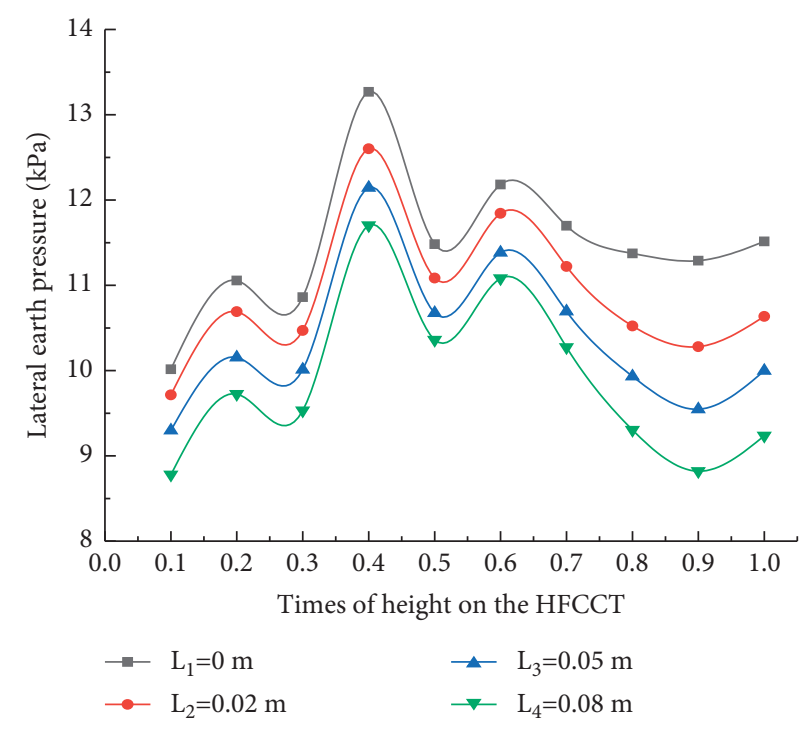

(b)

FIGURE 15: Earth pressure distribution for case C3: (a) VEP; (b) LEP.

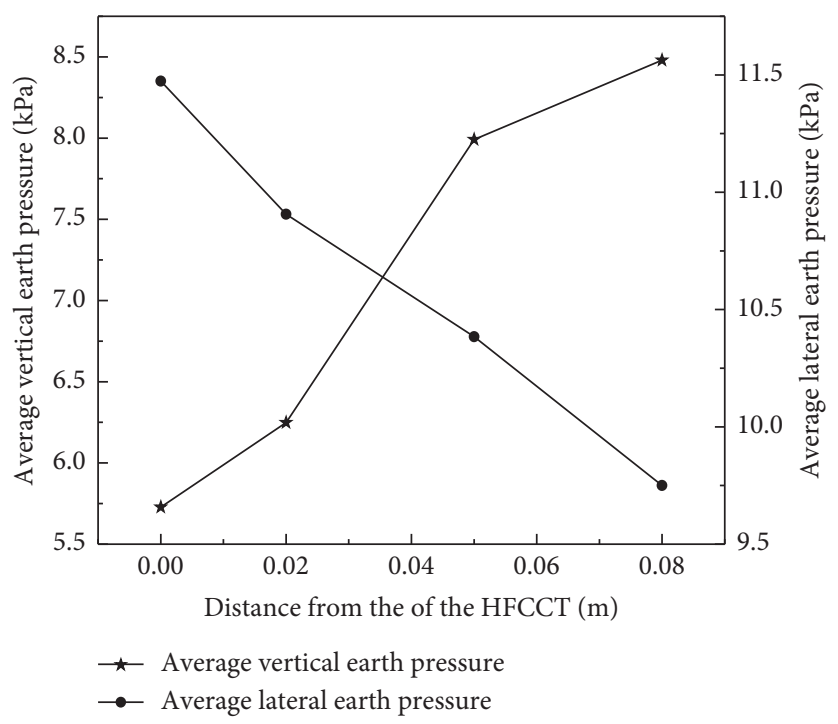

Figure 16: Average earth pressure for case C3.

of $0.17 \mathrm{~m}$ was the most reasonable, while the force around HFCCT was the most favorable.

(2) Variation of Displacement. The effect on RVD and equal settlement plane for case C5 is shown in Figure 25. RVD distribution was approximately in accordance with that of height of equal settlement plane, which increased first and then decreased with increasing $\mathrm{CW}$ width. Both reached the maximum values, $-0.147 \mathrm{~mm}$ and $0.86 \mathrm{~m}$, respectively, at $\mathrm{CW}$ width of $0.17 \mathrm{~m}$.

(3) Variation of Microscopic Contact. Figure 26 shows contact force chains of soil particles for case C5. Contact force chains above $\mathrm{CW}$ became denser, and the trend of upper arch gradually increased above the HFCCT (see the blue curve in the figure); the load was larger as CW width increased from $0.17 \mathrm{~m}$ to $0.22 \mathrm{~m}$ (see the green arrow in the figure).

\section{Discussion}

According to simulation results of PFC2D, earth pressure distribution of HFCCT was different as load reduction measures changed. First, cross section type of the structure was optimized by changing cross section optimization coefficient to reduce earth pressure. In addition, earth pressure in HFCCT changed from inverted V-shaped distribution to 
Distance from the axis of HFCCT (m)

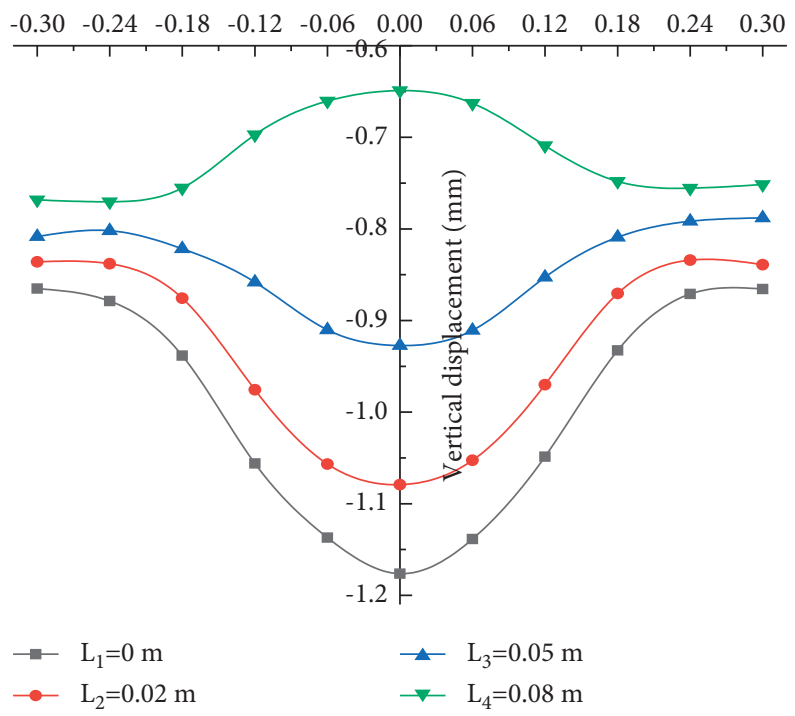

Figure 17: Vertical displacement for case C3.

Ball Extent displacement_y

Balls Extents (5773)

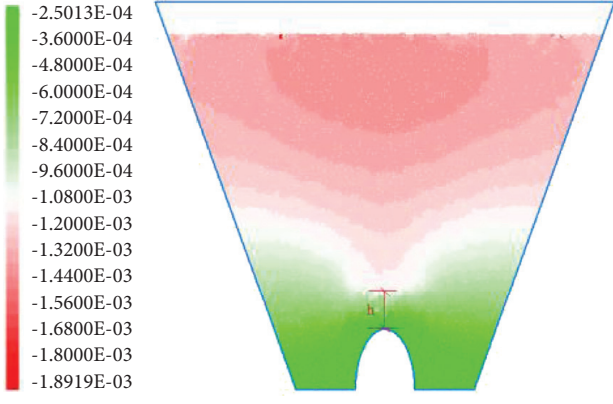

(a)
Ball Extent displacement_y Balls Extents (5773)

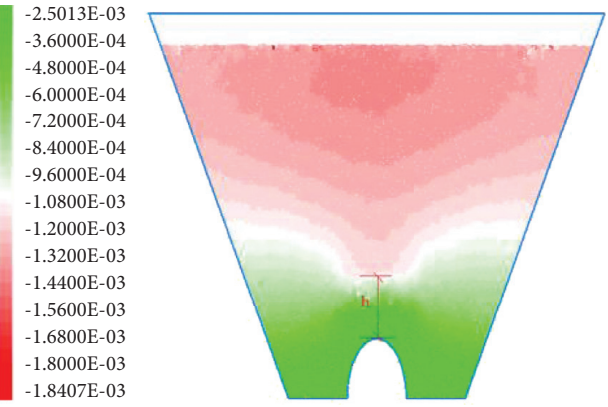

(b)

Figure 18: Vertical displacement nephograms of soil particles for case C3: (a) $L=0 \mathrm{~m}$; (b) $L=0.08 \mathrm{~m}$.

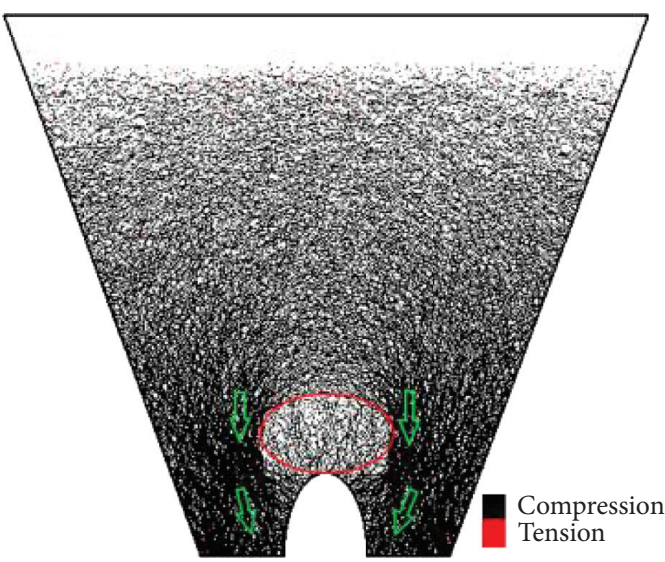

(a)

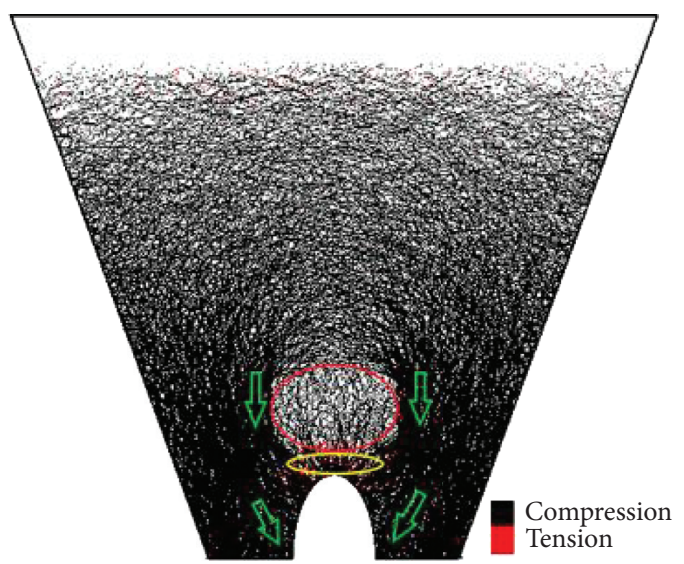

(b)

FIGURE 19: Distribution of contact force chains for case C3: (a) $L=0 \mathrm{~m}$; (b) $L=0.08 \mathrm{~m}$. 


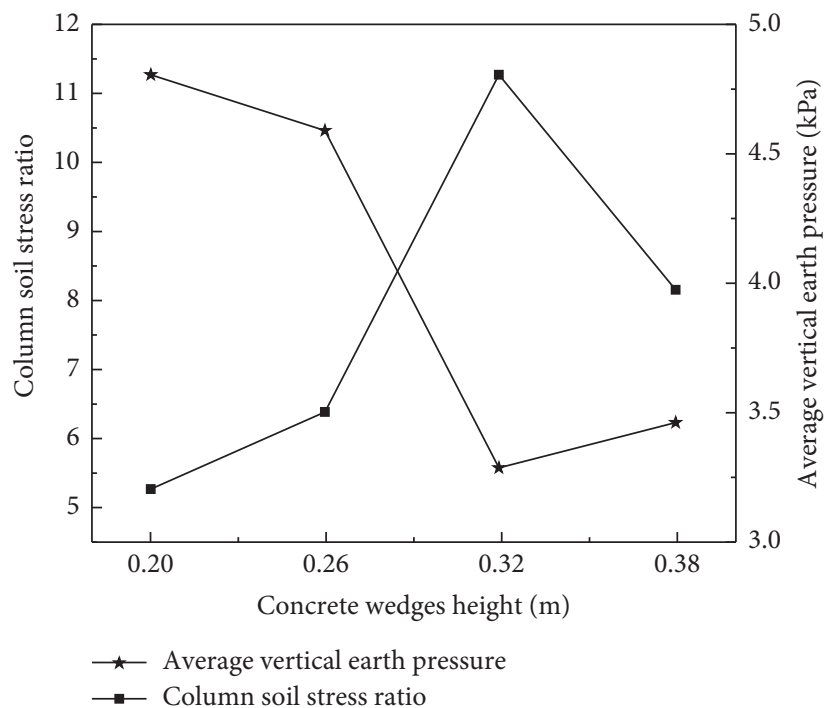

FIgURE 20: Average vertical earth pressure and the column-soil stress ratio for case C4.

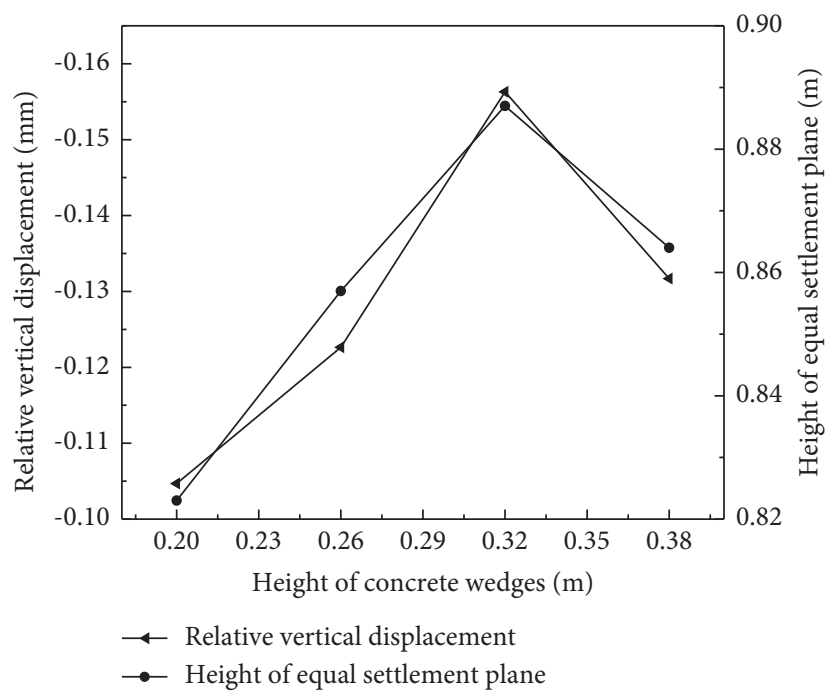

Figure 21: Relative vertical displacement and the height of equal settlement plane for case C4.

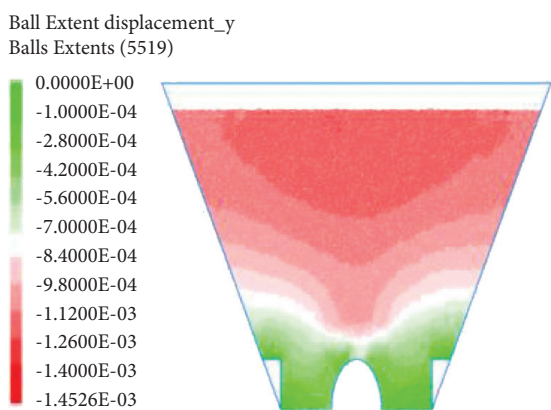

(a)

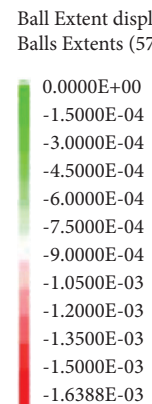

$-1.6388 \mathrm{E}-03$

Ball Extent displacement_y
Balls Extents (5589)

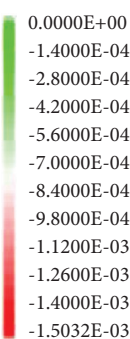

(b)

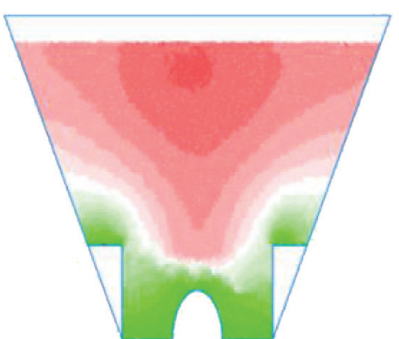

(c)

Figure 22: Vertical displacement nephograms of soil particles for case C4: (a) $H=0.20 \mathrm{~m}$; (b) $H=0.32 \mathrm{~m}$; (c) $H=0.38 \mathrm{~m}$. 


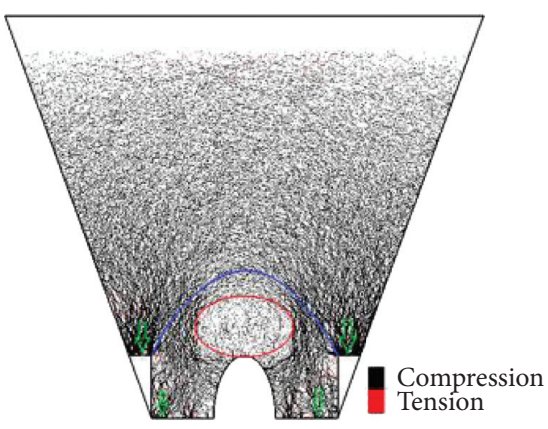

(a)

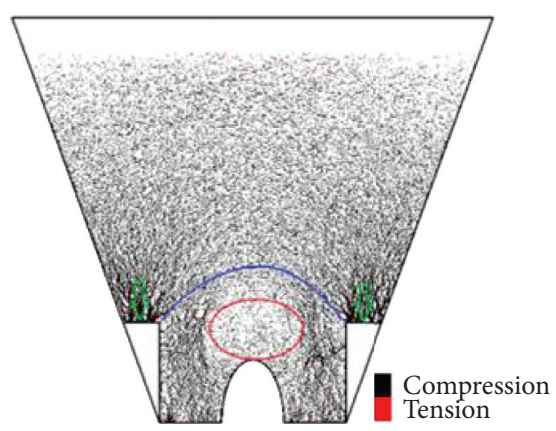

(b)

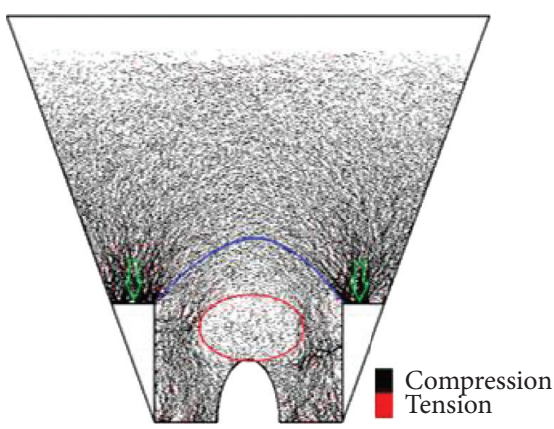

(c)

Figure 23: Distribution of contact force chains for case C4: (a) $H=0.20 \mathrm{~m}$; (b) $H=0.32 \mathrm{~m}$; (c) $H=0.38 \mathrm{~m}$.

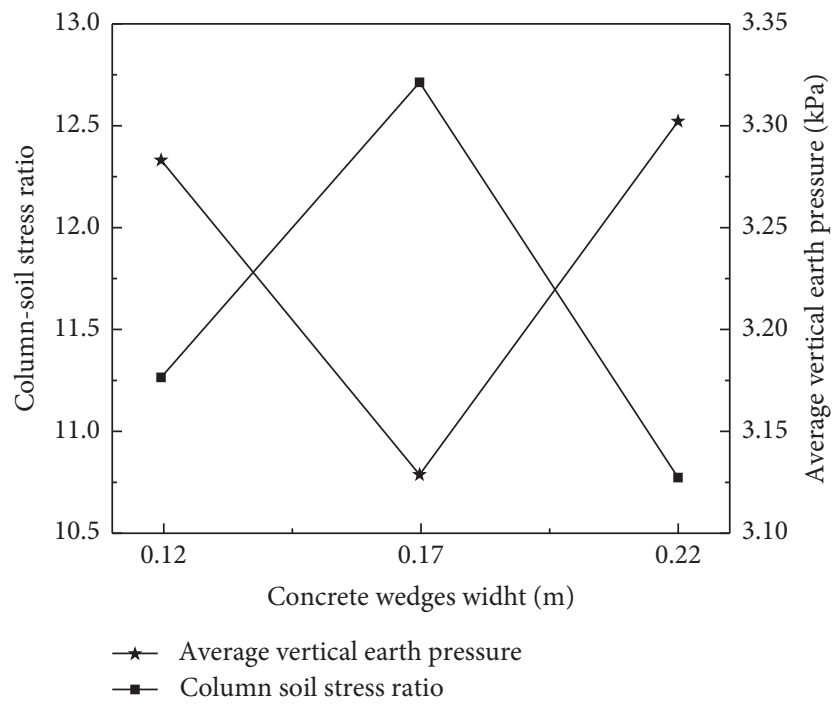

FIgURE 24: Average vertical earth pressure and the column-soil stress ratio for case C5.

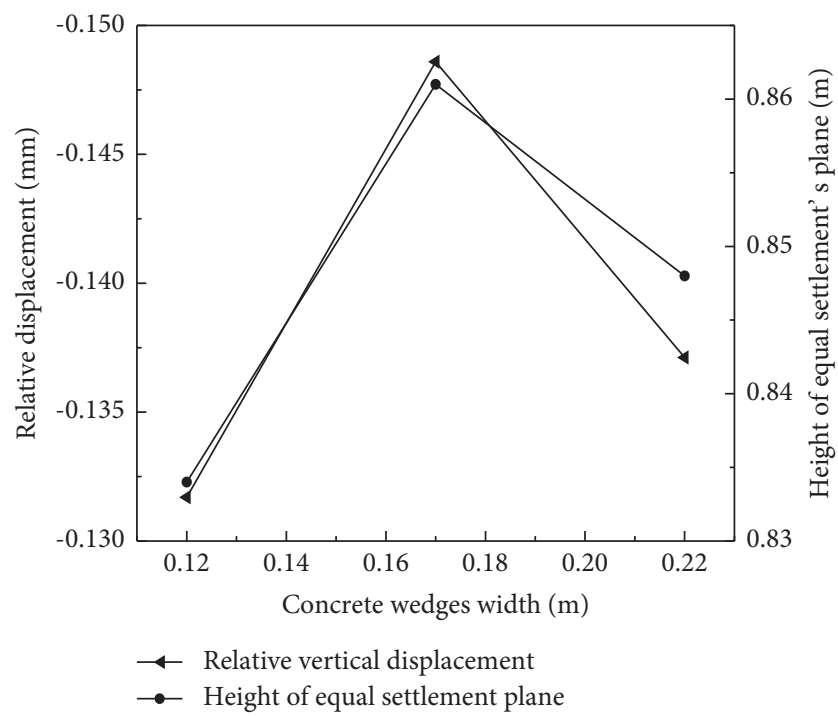

FIGURE 25: Relative vertical displacements and the height of equal settlement plane for case C5. 


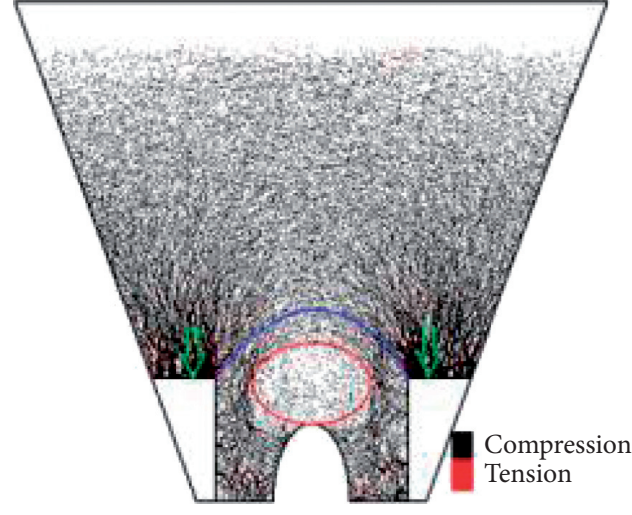

(a)

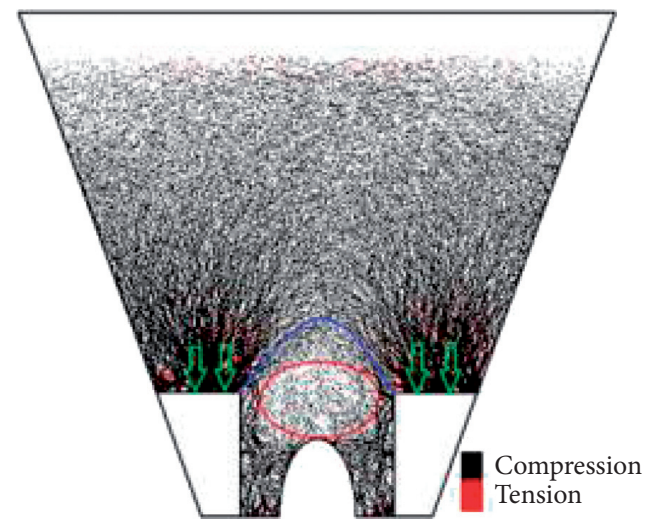

(b)

Figure 26: Distribution of contact force chains for case C5: (a) $W=0.17 \mathrm{~m}$; (b) $W=0.22 \mathrm{~m}$.

U-shaped distribution, and earth pressure was greatly reduced by combining the optimized section type of HFCCT with EPS. Furthermore, earth pressure of HFCCT can further be reduced by combining optimized section type with EPS and CW.

Under the conditions of ultrahigh backfill, the combination of optimized section type with EPS and CW can effectively reduce earth pressure and improve the safety of the structure. We evaluated the variations in earth pressure and VD of soil particles around HFCCT under three measures when backfill material around HFCCT was only loess. In the modeling process, HFCCT structure and foundation are regarded as rigid bodies. In practice, HFCCT is a three-dimensional mechanical structure, while it is only simulated as a two-dimensional structure in this paper. Therefore, subsequent studies should use PFC3D simulation analyses. In addition, other influencing factors such as the height and width of EPS were not evaluated. However, we established the influence of the three measures on earth pressure distribution on HFCCT.

\section{Conclusions}

The PFC2D software was used to assess the influence of different cross section types and load reduction material characteristics on earth pressure distribution around HFCCT. The optimal values of effects under three load reduction measures were obtained. Several conclusions can be drawn from this study:

(1) Earth pressure distribution was optimized by changing the cross section optimization coefficient of HFCCT. As cross section optimization coefficient increased, average VEP, RVD, and height of equal settlement plane first decreased and then increased, while the average LEP first increased and then decreased. The turning point was the cross section optimization coefficient of 1.0. Therefore, the most beneficial vault for HFCCT structure was determined as the cross section optimization coefficient $\lambda=1.0$ in terms of changing the cross section type.
(2) The combination of optimized section type of HFCCT with EPS load reduction significantly changed earth pressure distribution through its compressibility, which transferred the load from the top of HFCCT to the sides of HFCCT. From the perspective of changing the density and laying location of EPS, when the density of $\rho$ was $15 \mathrm{~kg} / \mathrm{m}^{3}$ while the laying location of $L$ was $0 \mathrm{~m}$, the average VEP, RVD, and height of equal settlement plane was advantageous. Therefore, an optimal density of $15 \mathrm{~kg} / \mathrm{m}^{3}$ is recommended, and EPS should be laid near the top of HFCCT during actual construction to achieve better load reduction effects.

(3) The combination of optimized section type with EPS and CW load reduction further changed earth pressure distribution, which reduced soil settlement on both sides of HFCCT and indirectly increased the settlement of internal soil column. A larger settlement difference was formed, which reduced the VEP on top of HFCCT. Moreover, the load reduction effect was different with the change in height and width of CW. When height was $0.32 \mathrm{~m}$ and width was $0.17 \mathrm{~m}$, the average VEP, RVD, and height of equal settlement plane were favorable. Thus, an optimal CW height of $0.32 \mathrm{~m}$ and width of $0.17 \mathrm{~m}$ are recommended for effective load reduction.

\section{Data Availability}

The data used in this work are available from the corresponding author by request.

\section{Conflicts of Interest}

The authors declare that they have no conflicts of interest.

\section{Acknowledgments}

This study was supported by the National Natural Science Foundation of China (51668036 and 51868041) and the Basic Research Innovation Group Project of Gansu Province (21JR7RA347). 


\section{References}

[1] A. Marston, "The theory of external loads on closed conduits in the light of the latest experiments," Proceedings of the Highway Research Board, pp. 138-170, 1930.

[2] N. G. Larsen and J. G. Hendrickson, "A practical method for constructing rigid conduits under high fills,"vol. 41, pp. 273-280, in Proceedings of the 41st Annual Meeting of the Highway Research Board, vol. 41, pp. 273-280, Highway Research Board, Washington, DC, USA, January 1962.

[3] R. K. Taylor, "Induced trench method of culvert installation," Proceedings of the Highway Research Board, vol. 52, no. 52, pp. 271-277, 1973.

[4] R. P. McAffee and A. J. Valsangkar, "Geotechnical properties of compressible materials used for induced trench construction," Journal of Testing and Evaluation, vol. 32, no. 2, pp. 143-152, 2004.

[5] M. G. Spangler, "A practical application of the imperfect ditch method of construction,"vol. 37, pp. 271-277, in Proceedings of the 30 Annual Meeting of the Highway Research Board, vol. 37, pp. 271-277, Highway Research Board, Washington, DC, USA, January 1958.

[6] J. Vaslestad, T. H. Johansen, and W. Holm, "Load reduction on rigid culverts beneath highfills: long-term behavior," Transporation Research Board, vol. 1415, pp. 58-68, 1993.

[7] A. Q. Gu, T. T. Guo, and X. P. Wang, "Experimental study on reducing load measurement using EPS of culvert under highstacked soil," Chinese Journal of Geotechnical Engineering, vol. 27, no. 5, pp. 500-504, 2005, in Chinese.

[8] B. L. McGuigan and A. J. Valsangkar, "Centrifuge testing and numerical analysis of box culverts installed in induced trenches," Canadian Geotechnical Journal, vol. 47, no. 2, pp. 147-163, 2010.

[9] M. A. Meguid, M. G. Hussein, M. R. Ahmed, Z. Omeman, and J. Whalen, "Investigation of soil-geosynthetic-structure interaction associated with induced trench installation," Geotextiles and Geomembranes, vol. 45, no. 4, pp. 320-330, 2017.

[10] J. J. Zheng, Q. Ma, and J. Zhang, "Calculation of vertical earth pressure on load reduction culverts under embankments by reinforcement," Chinese Journal of Geotechnical Engineering, vol. 33, no. 7, pp. 1135-1141, 2011, in Chinese.

[11] M. R. Ahmed, V. D. H. Tran, and M. A. Meguid, "On the role of geogrid reinforcement in reducing earth pressure on buried pipes: experimental and numerical investigations," Soils and Foundations, vol. 55, no. 3, pp. 588-599, 2015.

[12] H. E. Naggar, A. Turan, and A. Valsangkar, "Earth pressure reduction system using geogrid-reinforced platform bridging for buried utilities," Journal of Geotechnical and Geoenvironmental Engineering, vol. 141, no. 6, pp. 1943-5606, 2015.

[13] S. Li, I. H. Ho, L. Ma, Y. X. Yao, and C. D. Wang, "Load reduction on high-filled cut-and-cover tunnel using discrete element method," Computers and Geotechnics, vol. 114, 2019.

[14] S. Li, L. Ma, I. H. Ho, C. D. Wang, B. T. Yu, and P. Zhou, "Modification of vertical earth pressure formulas for high fill cut-and-cover tunnels using experimental and numerical methods," Mathematical Problems in Engineering, vol. 2019, no. 1, Article ID 8257157, 19 pages, 2019.

[15] S. Li, G. Q. Han, I. H. Ho, L. Ma, Q. C. Wang, and B. T. Yu, "Coupled effect of cross-sectional shape and load reduction on high-filled cut-and-cover tunnels considering soil-structure interaction," International Journal of Geomechanics, vol. 20, no. 7, pp. 1943-5622, 2020.
[16] S. Li, Y. X. Yao, I. H. Ho, L. Ma, and Q. C. Wang, "Coupled effect of expanded polystyrene and geogrid on load reduction for high-filled cut-and-cover tunnels using the discrete element method," International Journal of Geomechanics, vol. 20, no. 6, pp. 1943-5622, 2020.

[17] S. Li, Y. C. Jianie, I. H. Ho, L. Ma, Q. C. Wang, and B. T. Yu, "Experimental and numerical analyses for earth pressure distribution on high-filled cut-and-cover tunnels," KSCE Journal of Civil Engineering, vol. 4, pp. 1-11, 2020.

[18] A. Dasgupta and B. Sengupta, "Large-scale model test on square box culvert backfilled with sand," Journal of Geotechnical Engineering, vol. 117, no. 1, pp. 156-161, 1991.

[19] R. M. Bennett, S. M. Wood, E. C. Drumm, and N. R. Rainwater, "Vertical loads on concrete box culverts under high embankments," Journal of Bridge Engineering, vol. 10, no. 6, pp. 643-649, 2005.

[20] K. Kim and C. H. Yoo, "Design loading on deeply buried box culverts," Journal of Geotechnical and Geoenvironmental Engineering, vol. 131, no. 1, pp. 20-27, 2005.

[21] B. L. McGuigan and A. J. Valsangkar, "Earth pressures on twin positive projecting and induced trench box culverts under high embankments," Canadian Geotechnical Journal, vol. 48, no. 2, pp. 173-185, 2011.

[22] G. Masoud, A. Ali, and M. Maziar, "Shear strength of top slab of reinforced concrete box culverts," ACI Structural Journal, vol. 116, no. 6, pp. 63-74, 2019.

[23] H. Vladimir, E. Jan, and M. Lumir, "Shape optimization of concrete buried arches," Engineering Structures, vol. 48, pp. 716-726, 2013.

[24] B. L. McGuigan and A. J. Valsangkar, "Field monitoring and analysis of twin $3660 \mathrm{~mm}$ inside diameter induced trench culverts installed under $21.7 \mathrm{~m}$ of fill," Canadian Geotechnical Journal, vol. 48, no. 5, pp. 781-794, 2011.

[25] M. G. Spangler, "Underground conduits-an appraisal of modern research," Transactions of the American Society of Civil Engineers, vol. 113, no. 1, pp. 316-345, 1948.

[26] M. G. Spangler, "A theory of loads on negative projecting conduits," Highway Research Board in Proceedings of the 30th Annual Meeting of the Highway Research Board, vol. 30, pp. 153-161, Highway Research Board, Washington, DC, USA, January 1950.

[27] M. G. Spangler, Field Measurements of the Settlement Ratios of Various Highway Culverts, Iowa Engineering Experiment Station, Ames, IA, USA, 1950.

[28] R. P. McAffee and A. J. Valsangkar, "Field performance, centrifuge testing, and numerical modelling of an induced trench installation," Canadian Geotechnical Journal, vol. 45, no. 1, pp. 85-101, 2008.

[29] X. L. Wang, A. L. Zhang, T. Li, and S. S. Zhou, "Numerical simulation of covered culverts water surface profile at Jinan section in south-to-north water transfer project," in Proceedings of the Advances in Civil Engineering11 of the 5th International Conference on Bioinformatics and Biomedical Engineering, iCBBE), Wuhan, China, May 2011.

[30] L. Ma, S. Li, and Q. C. Wang, "Unloading model test on open cut tunnels in high filled loess trench," Chinese Journal of Rock Mechanics and Engineering, vol. 35, no. 5, pp. 1065-1071, 2016, in Chinese.

[31] S. Li, L. L. Zhao, I. H. Ho et al., "Influence of structural shape on earth pressure for high-filled cut-and-cover tunnel with and without load reduction based on discrete element method," Advances in Civil Engineering, vol. 2020, Article ID 8877873, 12 pages, 2020. 
[32] Itasca, PFC2D/3D User's Manual (Version 5.0), Itasca Consulting Group Inc., Minneapolis, MN, USA, 2016.

[33] M. J. Maynar and L. E. Rodríguez, "Discrete numerical model for analysis of earth pressure balance tunnel excavation," Journal of Geotechnical and Geoenvironmental Engineering, vol. 131, no. 10, pp. 1234-1242, 2005.

[34] S. Li, L. Ma, Q. C. Wang, S. Z. Li, J. X. Li, and Y. J. Zhang, "Model tests and numerical simulations of earth pressure for unloading structures of high fill open cut tunnel," Chinese Journal of Geotechnical Engineering, vol. 38, no. 4, pp. 636642, 2016, in Chinese.

[35] Y. X. Yao, Analysis on Meso-Mechanism of Soil Arching for Unloading Structure of High-Filled Cut-And-Cover Tunnel Based on DEM, Lanzhou Jiaotong University, Lanzhou, China, 2020, in Chinese. 